Review

\title{
Circular Economy Strategies for Equipment Lifetime Extension: A Systematic Review
}

\author{
Alessandro Fontana ${ }^{1, *}$, Andrea Barni ${ }^{1}\left(\mathbb{D}\right.$, Deborah Leone ${ }^{1}\left(\mathbb{D}\right.$, Maurizio Spirito ${ }^{2}$, Agata Tringale ${ }^{2}$, \\ Matteo Ferraris ${ }^{2}$, Joao Reis ${ }^{3}$ and Gil Goncalves ${ }^{3}$ \\ 1 Department of Innovative Technologies, University of Applied Sciences and Arts of Southern Switzerland, \\ 6928 Manno, Switzerland; andrea.barni@supsi.ch (A.B.); deborah.leone@supsi.ch (D.L.) \\ 2 International Trends and Opportunities, LINKS Foundation, 10138 Torino, Italy; \\ maurizio.spirito@linksfoundation.com (M.S.); agata.tringale@linksfoundation.com (A.T.); \\ matteo.ferraris@linksfoundation.com (M.F.) \\ 3 SYSTEC, Faculty of Engineering, University of Porto, 4200-465 Porto, Portugal; jpcreis@fe.up.pt (J.R.); \\ gil@fe.up.pt (G.G.) \\ * Correspondence: alessandro.fontana@supsi.ch; Tel.: +41-(0)58-666-65-69
}

Citation: Fontana, A.; Barni, A.; Leone, D.; Spirito, M.; Tringale, A.; Ferraris, M.; Reis, J.; Goncalves, G. Circular Economy Strategies for Equipment Lifetime Extension: A Systematic Review. Sustainability 2021, 13, 1117. https://doi.org/ $10.3390 /$ su13031117

Received: 15 December 2020

Accepted: 13 January 2021

Published: 21 January 2021

Publisher's Note: MDPI stays neutral with regard to jurisdictional claims in published maps and institutional affiliations.

Copyright: (c) 2021 by the authors. Licensee MDPI, Basel, Switzerland. This article is an open access article distributed under the terms and conditions of the Creative Commons Attribution (CC BY) license (https:/ / creativecommons.org/licenses/by/ $4.0 /)$.

\begin{abstract}
Even if the economy nowadays is still locked into a linear model of production, tighter environmental standards, resource scarcity and changing consumer expectations are forcing organizations to find alternatives to lighten their impacts. The concept of Circular Economy (CE) is to an increasing extent treated as a solution to this series of challenges. That said, the multitude of approaches and definitions around CE and Life Cycle Extension Strategies (LCES) makes it difficult to provide (Small and Medium Enterprise) SMEs with a consistent understanding of the topic. This paper aims at bridging this gap by providing a systematic literature review of the most prominent papers related to the $\mathrm{CE}$ and lifetime extension, with a particular focus on the equipment and machinery sector. A taxonomy was used to define and cluster a subset of selected papers to build a homogeneous approach for understanding the multiple strategies used in the industry, and the standards in maintenance and remanufacturing strategies. As a final research step, we also propose a Strategy Characterization Framework (SCF) to build the ground for the selection of the best strategy to be applied for production equipment life cycle extension on several industrial use cases.
\end{abstract}

Keywords: circular economy strategies; life cycle extension strategies; digitalization in life cycle extension

\section{Introduction}

Earth's ecosystem is showing the tremendous effects of the linear consumption model that distinguish our society. Resources are relentlessly drained in the sake of a consumerismbased consumption model, with the effect that the global ecological footprint of human activities has increased from less than one planet Earth in 1961, to more than 1.4 planet Earths in 2005, with projections leading to two planet Earths around 2030 [1].

Against this trend, the concept of Circular Economy has been coined, referring to an industrial economy that is restorative by intention; aims to rely on renewable energy; minimizes, tracks, and hopefully eliminates the use of toxic chemicals; and eradicates waste through careful design [2]. According to the CE message, the inner circles of Figure 1 (reuse, remanufacturing and refurbishment) demand fewer resources and energy than conventional recycling of materials as low-grade raw materials. The time spent by the resources within the inner circles should be maximized and the adoption of Lifecycle Extension strategies (LCES) favored [3]. 


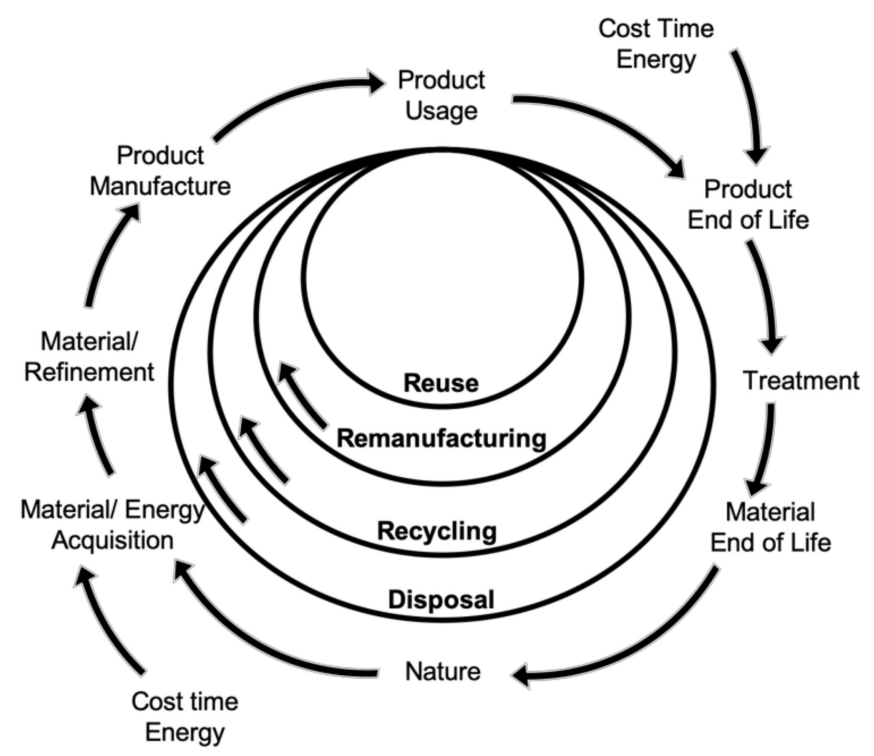

Figure 1. Product value retention in a Circular Economy (CE) model. Adapted from [4].

According to the presented model, the product value chain and life cycle retain the highest possible value and quality as long as possible and is also as energy efficient as it can be.

Trying to put the theoretical definition into action, European Commission is pushing the boundaries of its implementation by promoting founding schemes and initiatives to support and drive the systemic integration of circular behaviors into the European economic and social system [5]. As a matter of fact, CE is nowadays shifting from a nice to have marketing operation, to a business development strategy central to the restoring and preservation of our natural ecosystem [6]. However, despite the motivated promoting efforts, the concrete application of the model at the micro-level is still in its infancy due to several challenges that companies face [7-9].

One of the key aspects being nowadays explored related to the next generation of manufacturing systems is the focus on the reuse of waste materials and equipment in End of Life (EoL). The impact of Circular Economy strategies, in particular for LCES has gained strength and was somehow refreshed with the introduction of digitalization, mainly through the 4th industrial revolution [10-12]. Based on the concept of the digital twin, which simplistically is a digital replica of shop-floor equipment, data can be collected, processed and synchronized with Information Systems and more knowledge can be generated and gained for wiser and more informed decisions [13]. As for LCES, the digitalization process allowed for a better understanding of the exogenous properties-such as physicochemical properties and dynamics of the process-together with the endogenous properties-focusing on the behavior of each component that composes the equipment. These aspects are particularly important for CE taking into account strategies related to equipment lifecycle extension. Without collected data and information about machine process capabilities and machine degradation/health, LCES is a very hard job to achieve [14].

Taking Resell and Reuse as an example, which is closely related with the concept of servitization in industry, without the correct machine data about maintenance logs, used parameters, product quality and degradation data, it is very hard to reliably resell a machine to a company or even reuse a machine for different purposes [15]. In the case an Original Equipment Manufacturer (OEM) resells equipment, quality assurance should be given to the customer. The problem is that the machine was used by a different customer, and hence, no information about its use is known. However, with the servitization concept software modules can be installed in the machine itself, as a digital twin, and predictive models about maintenance, degradation and quality can be built based on collected data, and afterward resold to the new customer. Complemented with other relevant information 
and contracting, this can be seen as the required assurance for the new customer, taking into account also the importance of economic, social and psychological factors that affect customers to engage in the CE purchasing durable products and seeking to repair products instead of disposing of them. In this context, the capability of businesses to exploit technological advancements as enablers for the adoption and diffusion of CE models and practices, together with the strong consumer engagement allowing to make these models flourish, is a prerequisite for the success of the CE model itself.

The present paper focuses on a systematic literature review of lifetime extension strategies for CE, adopting the PRISMA guidelines [16]. Compared to the available literature reviews in this context, that consider LCES as a part of CE, this work focuses on LCES and is specifically devoted to providing academia and industry concrete elements to guide the implementation of LCES into daily activities. In doing so, it aims to answer two main questions, both motivated by the limited and somehow scattered literature related to LCES, and by the need of providing academia and practitioners instruments to support a better understanding of which CE strategies are most relevant and indicated for each specific situation:

- Which is the state of research related to equipment lifetime extension strategies and their definition?

- Which are the possible elements to be extracted from literature to implement the LCES from the technical and business point of view?

The results of the work are meant to extend the current theoretical knowledge related to LCES by providing a thorough review of the current edited works, either in terms of literature studies, patents and standards. The works are systematically analysed through a taxonomy designed according to the identified research questions.

As a result of the review, a set of definitions of the identified strategies is proposed. The definitions have the scope of homogenising the different perspectives found in the literature domain for the same aspect or, whenever needed, proposing new definitions merging the different contributions and filling the identified literature gaps.

On top of the previous analysis, a Decision Support Framework (DSF) is proposed. The model, focusing its application on electromechanical machines and robotics systems, guides the identification of the optimal refurbishment and re-manufacturing strategies, offering machine lifetime extension plans that, together with the environmental benefits, guarantee increased productivity. The model is then tested to provide readers indications on how to apply it.

The paper is therefore organized into four sections. Section 2 focuses on the review methodology used for selecting and analyzing the most suitable papers given the current topic of LCES in the perspective of both existing papers and patents. Section 3 provides a summary and brief individual evaluation of all the selected papers through a taxonomy lens, which was essential to uniform the understanding of the multiple strategies. Additionally, a central piece of the paper is the framing of all papers into the newly revised taxonomy, so a complete and condensed review of the results is presented. Finally, and to better contextualize the importance of the paper review, a set of standards is presented related to Maintenance and Remanufacturing. Further on, in Section 4, as a complementary activity, a small set of standards in maintenance and remanufacturing strategies was performed. As a result of the performed review and standard analysis, the next research steps are suggested proposing a Strategy Characterization Framework (SCF), together with some consideration on the relation between literature and patent trends. Section 5 wraps up the paper by drawing some major conclusions of the work.

\section{Review Methodology and Trend Analysis}

This section is meant to present the review protocol exploited in this work, based on the approach suggested by [17]. This resulted in four different stages, from gathering all publications to the classification of each paper into the defined taxonomy. Additionally, a paper and patent trend analysis are presented, covering the last 10 years of developments. 
A perspective on the evolution of this area is thus contemplated, together with a set of related standards, giving indications on regulations driving $\mathrm{CE}$ implementation in the industrial domain.

\subsection{Review Methodology}

2.1.1. Gathering the Publications and Patents

As the first step of the literature review, publications were gathered exploiting the database and the keyword reported in Table 1.

Table 1. Main boundaries of literature and patents review.

\begin{tabular}{cc}
\hline Boundary & Description \\
\hline Database used & Science direct (Elsevier); Web of Science; Lens patent; Google \\
patent. & Circular economy strategies, Lifecycle extension strategies, \\
Lifecycle extension industrial/production equipment, & Digitalization and lifetime extension. \\
Research Keywords & From 2002 up to 2020, with the majority of the studies \\
Year considered & concentrated from 2010. The only exception is a 1995 publication, \\
considered as the ancestor of life extension topic. & Scientific articles in English were considered for the analysis. \\
Language & Scientific papers and conference papers. \\
Article type & Published. \\
Publication status & Granted. \\
Patent status &
\end{tabular}

\subsubsection{Identifying Topic References}

Figure 2 shows the adopted research strategy. Starting from a first search of the Research Keywords in the field "Topic" in the Web of Science search engine, and "Title, abstract and author-specified keywords" in the Science direct search engine, the records identified by searching the database are 2539, 1671 form Web of Science and 868 from Science direct. After duplicates are removed, 1200 papers are taken into consideration. The second step of the review implies a first screening of the bibliographic references through title and abstract analysis, in order to identify the ones that are providing a valuable contribution to the understanding of the LCES subject. A total of 989 scientific papers were excluded, thus 211 publications remain with titles and abstracts dealing with the identified topics and were fully assessed for eligibility. Finally, by applying the two research questions above mentioned as a refining criterion, a final amount of 75 documents was considered as reference literature and assessed in detail.

\subsubsection{Taxonomy Definition}

The third phase of the review methodology is a reasoned examination of the papers' text to understand the possible contribution of the literature to the topic considering a wide perspective (e.g., economic and environmental impacts, indicators, business consequences, etc.). This evaluation was guided by the development of a Taxonomy that was exploited to pre-classify the publications and then classify the contributions. As suggested by [18] the taxonomy was designed with the intent of delimiting and classifying the different contributions on the topic discussed in the paper. As a taxonomy not only includes the classification system but also, the theory on which the classification system is built and the methods employed to construct it [19]. The taxonomy definition takes the steps from the research questions above mentioned. Concerning the state of research, the literature findings were classified grouping the ones related to literature analysis on the field of $\mathrm{CE}$ strategies. Special attention was also dedicated to the publications specifically addressing life cycle extension amongst CE strategies, production equipment and LCES. A focal point related to state of the art is moreover related to works providing definitions of LCES so that strategies are clearly identified. In order to satisfy these research needs, the following taxonomy fields were thus introduced: Literature Review, Life cycle Extension, Production 
Equipment, Strategies, Definition. With regards to the possibility to extract from literature elements for the implementation of LCSE (the second research objective), the taxonomy field identification was based on different publications that investigated the development of implementation frameworks for corporate sustainability [20-23].

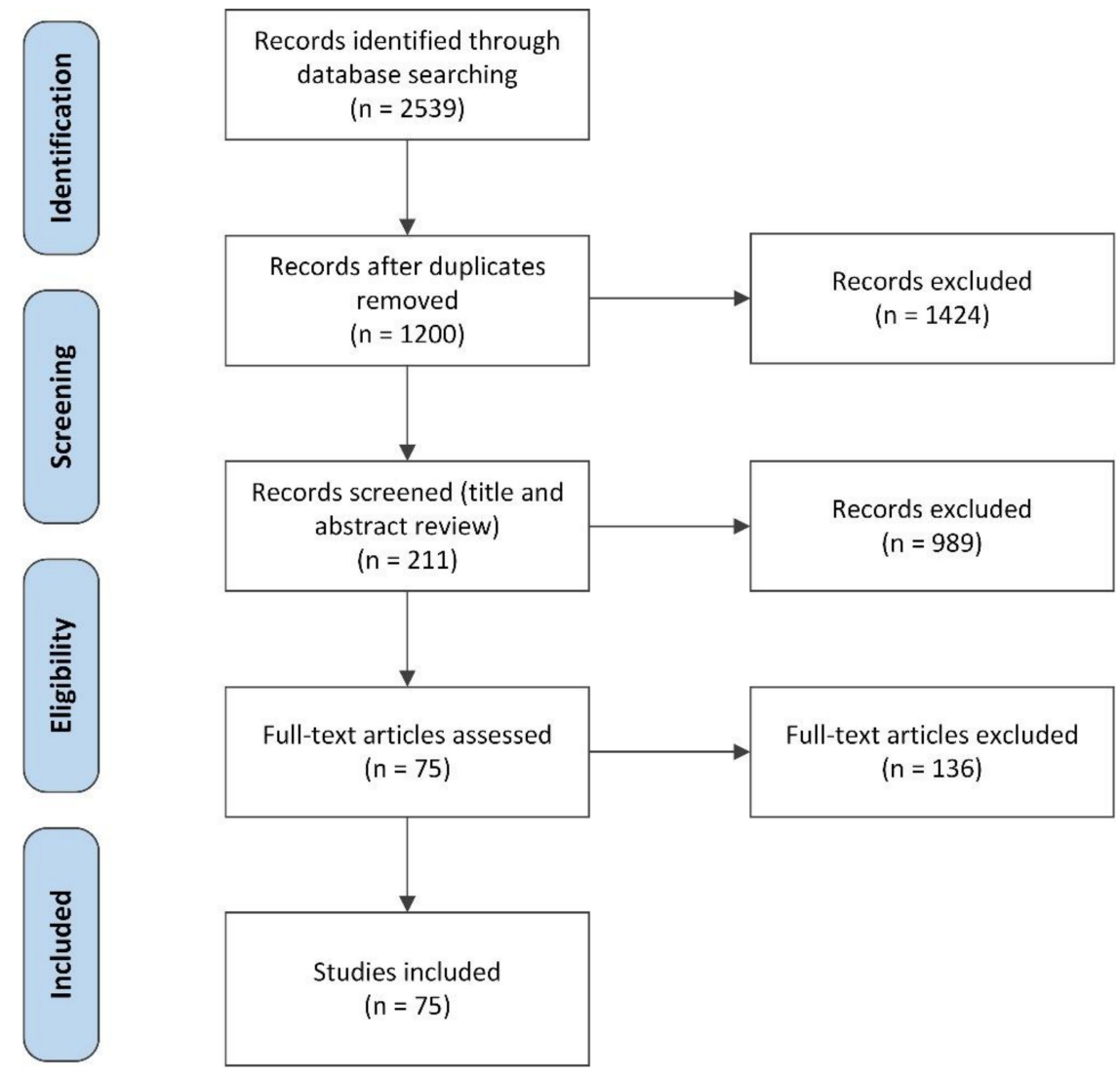

Figure 2. PRISMA flow diagram applied to the work.

All these works share a common approach for the actual implementation of sustainability concepts (and thus, extending the scope, applicable also to the CE ones) that is funded in planning, activate initiatives and measure the results and the impacts obtained. Following this framework, literature findings were categorized considering the following taxonomy fields: Description and Implementation Guidelines (planning), Business Models and Digitalization and Lifetime Extension (activate initiatives) and Metrics and Evaluation Methodologies (measure).

Hereinafter, the definition of the taxonomy fields is detailed in Table 2.

\subsubsection{Classification Through the Taxonomy}

The last step of the review methodology here considered is the classification of the research results via the taxonomy, presented in Table 3. 
Table 2. Taxonomy fields.

\begin{tabular}{|c|c|c|}
\hline Taxonomy Field & Research Question & Field Scope \\
\hline Literature Review & State of research & $\begin{array}{l}\text { It is meant to select the papers that are providing an } \\
\text { extensive literature review on the LCES or on the related } \\
\text { topics. }\end{array}$ \\
\hline Life cycle Extension & State of research & $\begin{array}{l}\text { It investigates whether the publication is considering the life } \\
\text { cycle extension concept, directly or indirectly mentioning it. }\end{array}$ \\
\hline Production Equipment & State of research & $\begin{array}{l}\text { It discriminates if the publication is specifically dealing with } \\
\text { production equipment. }\end{array}$ \\
\hline Strategies & State of research & $\begin{array}{l}\text { It is discriminating if the publication in analysis is } \\
\text { presenting strategies to extend the life cycle of products. } \\
\text { It allows identifying the papers providing a precise }\end{array}$ \\
\hline Definition & State of research & $\begin{array}{c}\text { definition of the LCES. This field was introduced since a } \\
\text { preliminary analysis of the research results revealed that } \\
\text { some unclear or even conflicting definitions of strategies are } \\
\text { proposed in the literature. }\end{array}$ \\
\hline $\begin{array}{c}\text { Description and } \\
\text { Implementation Guidelines }\end{array}$ & Implementation & $\begin{array}{l}\text { It is meant to establish whether the publication in analysis is } \\
\text { providing a description of the strategy application in the } \\
\text { industrial context, or even is proposing guidelines that } \\
\text { could actually support the implementation of the strategy } \\
\text { presented. }\end{array}$ \\
\hline $\begin{array}{l}\text { Metrics and Evaluation } \\
\text { Methodologies }\end{array}$ & Implementation & $\begin{array}{l}\text { It investigates if the paper is presenting metrics and } \\
\text { indicators to evaluate the effects of the strategy } \\
\text { implementation from the economic and environmental } \\
\text { point of view, or evaluation methodologies enabling } \\
\text { discrimination between the diverse LCES. }\end{array}$ \\
\hline Business Models & Implementation & $\begin{array}{c}\text { It is meant to identify the publications presenting a business } \\
\text { view related to the LCES application in the form of a } \\
\text { possible business model to be concretely applied in the } \\
\text { industrial application. }\end{array}$ \\
\hline $\begin{array}{l}\text { Digitalization and Lifetime } \\
\text { Extension }\end{array}$ & Implementation & $\begin{array}{c}\text { It describes how digitalization plays a crucial role to enable } \\
\text { more sustainable Circular Economy and how a product's } \\
\text { lifetime is extended thanks to digital innovation, with a } \\
\text { specific focus on the extension of the lifespan of machinery, } \\
\text { equipment and product. }\end{array}$ \\
\hline
\end{tabular}

Table 3. Publications per Taxonomy field.

\begin{tabular}{|c|c|}
\hline Taxonomy Field & Publications \\
\hline Literature Review & {$[24],[25],[26],[27],[28],[29],[30],[31],[32],[33],[34],[35]$} \\
\hline & [24], [25], [26], [27], [28], [29], [36], [37], [38], [39], [40], [41], [42], [43], [44], \\
\hline Life cycle Extension & $\begin{array}{c}{[45],[46],[47],[48],[49],[50],[51],[52],[53],[54],[55],[56],[57],[58],[59],} \\
{[60],[61],[62],[63]}\end{array}$ \\
\hline Production Equipment & {$[62]$} \\
\hline & {$[24],[25],[26],[27],[28],[30],[31],[32],[34],[36],[37],[38],[39],[40],[41]$,} \\
\hline Strategies & $\begin{array}{c}{[42],[43],[44],[45],[46],[47],[48],[49],[50],[51],[52],[57],[58],[59],[60],} \\
{[61],[62],[64],[65],[66],[67],[68],[69]}\end{array}$ \\
\hline Definition & $\begin{array}{c}{[25],[27],[28],[30],[33],[36],[37],[40],[42],[43],[44],[45],[46],[47],[48],} \\
{[49]}\end{array}$ \\
\hline Description and Implementation Guidelines & $\begin{array}{l}\text { [25], [28], [31], [33], [35], [39], [40], [41], [42], [44], [43], [45], [46], [47], [48], } \\
{[49],[50],[51],[52],[57],[61],[70],[65],[63],[66],[67],[71],[72],[73],[74]}\end{array}$ \\
\hline Metrics and Evaluation Methodologies & $\begin{array}{c}{[27],[29],[31],[32],[34],[36],[47],[48],[49],[50],[53],[54],[55],[58],[59],} \\
{[60],[64],[68],[69],[71],[72],[73],[74],[75]}\end{array}$ \\
\hline Business Models & {$[25],[26],[30],[35],[45],[46],[57]$} \\
\hline Digitalization and Lifetime Extension & $\begin{array}{c}\text { [11], [26], [30], [45], [76], [77], [78], [79], [80], [81], [82], [83], [84], [85], [86], } \\
\text { [87], [15], [88], [89], [90], [91] }\end{array}$ \\
\hline
\end{tabular}




\subsection{Trend Analysis}

Paper and Patent Trend Analysis presented hereinafter are meant to provide an overview of how the CE and LCES topics were addressed in the last 10 years, both by academics and industries.

\subsubsection{Paper Trend Analysis}

As a first step, an analysis in terms of number of publications and citations was performed in the Web of Science (WoS) online platform. Figure 3 depicts an exponentially growing trend in publications in the past 5 years, with close to $83 \%$ of all publications being between 2015 and 2019, with a total of 1262 publications. It can also be seen a slight growth between 2008 and 2010 but followed by a decrease in publications until 2015. As for the publications, the same trend can be observed in the last 5 years, with $95 \%$ of citations registered between 2015 and 2019, with a total of 9695 citations.

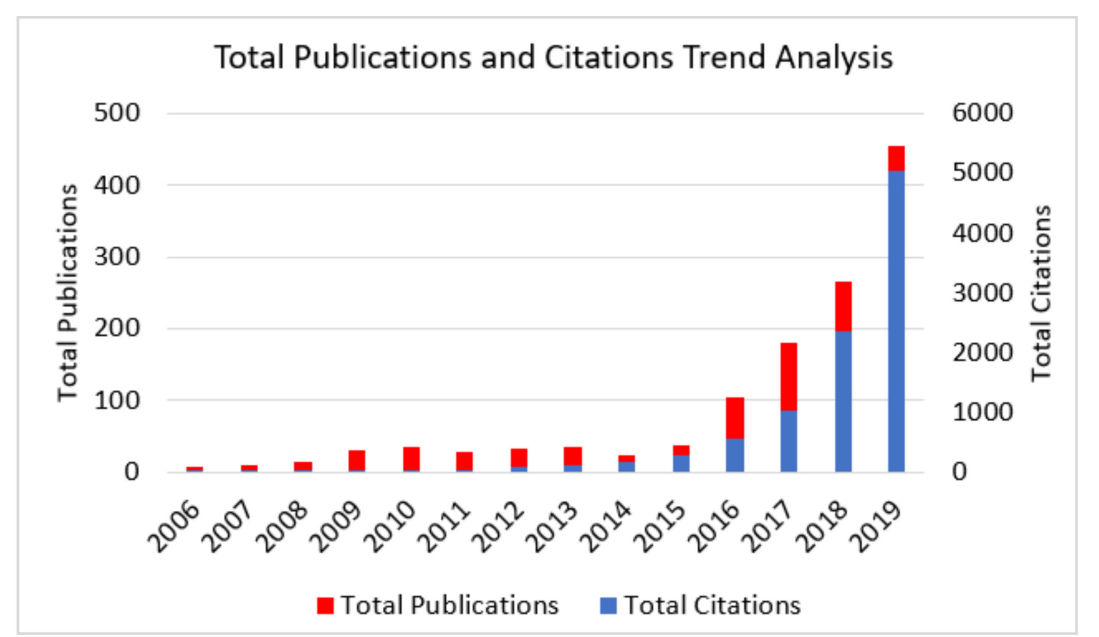

Figure 3. Trends of the CE publications and citations in manufacturing and industry-related topics.

The current analysis was based on a search in WoS with the topic keyword of "circular economy" and the keywords having "manufacturing" or "industry", or both, in the topic as well. Although there are already some results from 2019, those were excluded being considered not closed and still increasing until the end of the year, making those not suitable to be included in the analysis.

An analysis based on the publication trend of life cycle extension strategies was carried out considering the following search engines: Science Direct and Web of Science, in the period 2010-2019. Figure 4 represents the results of research showing non-linear behavior: the number of publications relating to the life cycle extension strategies varies from year to year, maintaining an increasing trend over the last few years.

A further analysis was performed focusing on the main trend of the papers related to how digitalization affects the product lifetime and the extension of machinery and equipment. The research was performed by using all the following search engines: Science Direct, Springer Link, Taylor Francis, Wiley Blackwell and Google Scholar. We selected the period from 2010 to 2019 considering the keywords related to "digitalization" and "lifetime extension" and their combination. Figure 5 and Table 4 highlight the results of the research showing a moderate but constant increase in the number of publications in digitalization and lifetime extension topics, respectively, and a steep increase in the combination of the two topics for the last four years. 


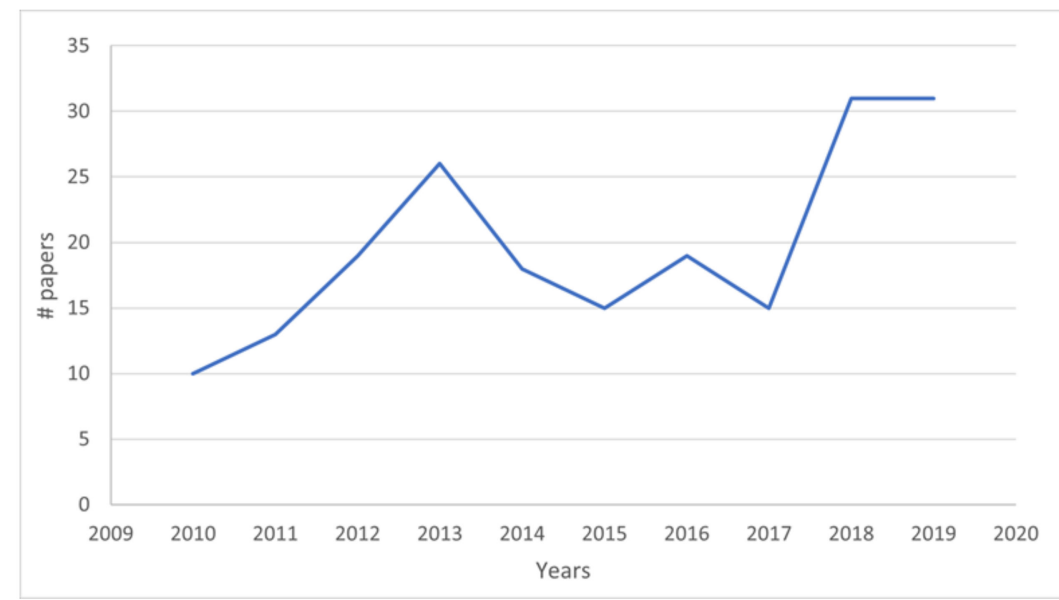

Figure 4. Trends of publications about Life Cycle Extension Strategies (LCES) (2010-2019).

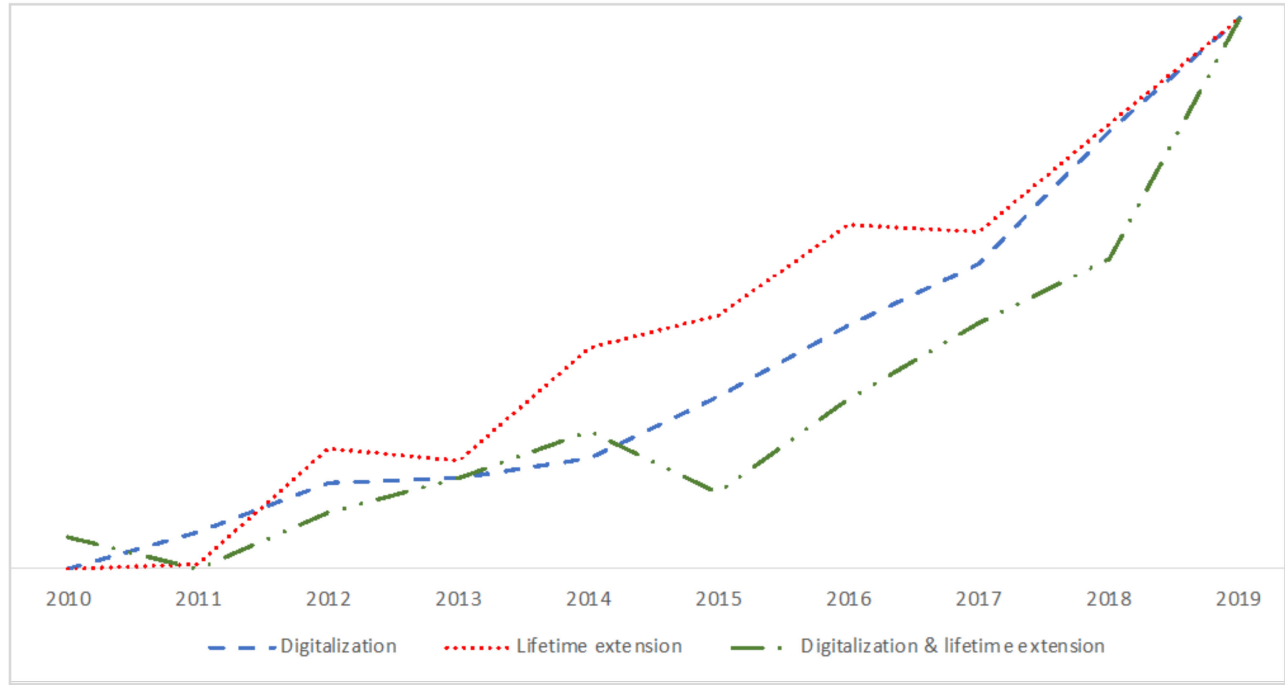

Figure 5. Trends of publications about "digitalization" and "lifetime extension" (2010-2019).

Table 4. Trends of publications about "digitalization" and "lifetime extension" (2010-2019).

\begin{tabular}{|c|c|c|c|c|c|c|c|c|c|c|}
\hline TOTAL & 2010 & 2011 & 2012 & 2013 & 2014 & 2015 & 2016 & 2017 & 2018 & 2019 \\
\hline Digitalization & 81,095 & 87,005 & 94,714 & 95,286 & 98,637 & 108,230 & 119,506 & 129,364 & 150,279 & 168,301 \\
\hline $\begin{array}{l}\text { Lifetime } \\
\text { extension }\end{array}$ & 804 & 811 & 993 & 972 & 1149 & 1198 & 1340 & 1328 & 1494 & 1661 \\
\hline $\begin{array}{l}\text { Digitalization } \\
\text { \& lifetime } \\
\text { extension }\end{array}$ & 12 & 3 & 19 & 29 & 42 & 25 & 51 & 73 & 91 & 160 \\
\hline
\end{tabular}

\subsubsection{Patent Trend Analysis}

A patent analysis was carried out using Lens Patent as the main database for our purpose. The research on trends was based on patents over the last 10 years (from 2010 to 2019). A first analysis was conducted on the Life cycle extension topic for the industry and manufacturing sector with the following keywords: "Circular economy", "Lifetime extension", Remanufacturing, Refurbishment AND equipment, Refurbishment AND machinery, Refurbishment AND "industrial machine", "Predictive maintenance", "Predictive maintenance" AND equipment, "Predictive maintenance" AND "industrial machinery", "Preventative maintenance", "Preventative maintenance" AND equipment, "Preventative maintenance" AND "industrial machine". These keywords are in line with the ones used 
for the analysis of trends in publications and citations and were selected with the aim to avoid too generic results, not pertinent to the purpose of this work. Our search strategy was related to the "granted" patent that is mentioned in the dataset under the following fields: title, abstract, full text and claims. We use a Boolean research strategy to get a representative sample excluding replication of patents. We obtained a final sample with 16,409 patents. Figure 6 highlights the number of patents is clearly increasing over the years, with an increasing marginal number in the last 2 years. The figure also shows a high concentration of countries where the US (73\% of the overall selected patents), Europe $(16 \%)$ and Australia (5\%) seem to have the most prominent role followed by China, South Korea, and Japan. The most prominent keywords in terms of the number we find in this analysis are "Preventative maintenance" (30.8\%), "Preventative maintenance" AND equipment (20\%), Refurbishment AND "industrial machine" (16.34\%), Remanufacturing (11.6\%), "Predictive maintenance" (8.34\%), "Predictive maintenance" AND equipment (5.92\%), Refurbishment AND equipment (3.79\%), "Lifetime extension" (1.5\%), “Circular Economy" (1.2\%).

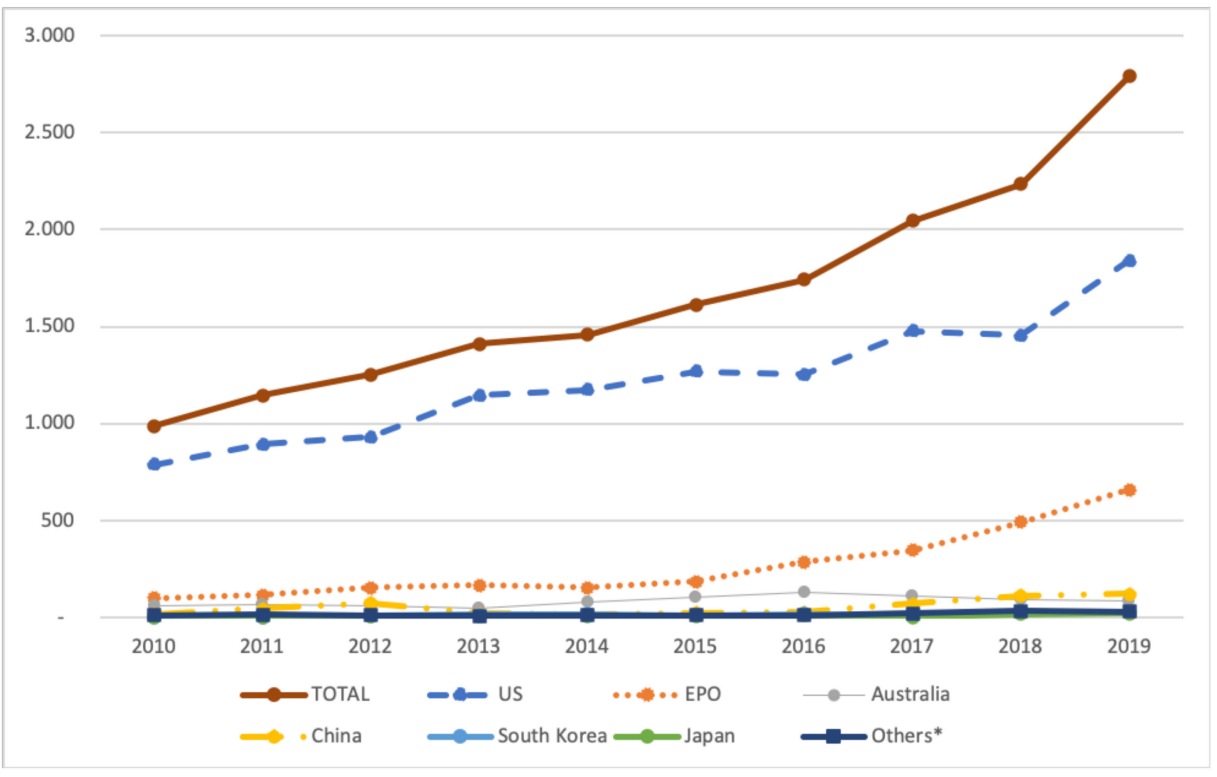

Figure 6. Annual and country trends of patents related to CE and Life Cycle Extension.

Thereafter, we made a focus on the patents related to digitalization and lifetime extension collecting information from Lens Patent e Google Patent. We find an increasing trend as shown in Figure 7 confirming the higher interest on the topic not only for the academic sector but also for the market. 


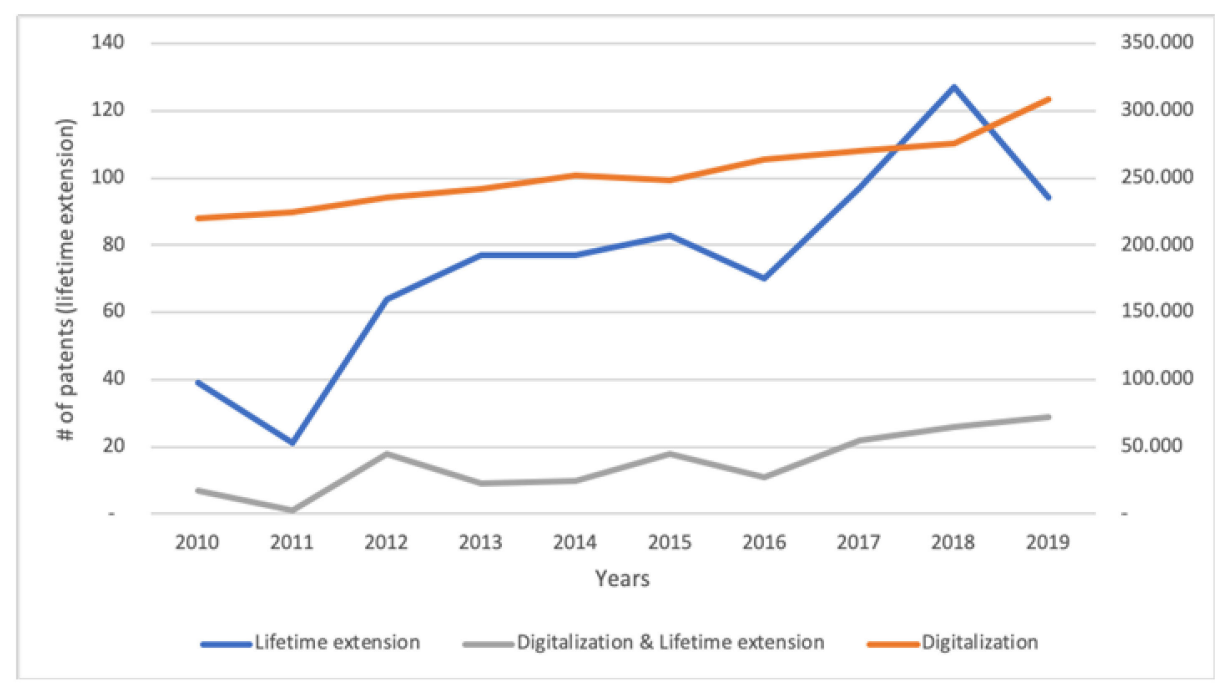

Figure 7. Annual trend of patents related to lifetime extension and digitalization.

\section{Analysis of the Literature}

Section 3 is dedicated to the analysis of the gathered publications. The review of the papers was conducted by first analyzing them through the lenses offered by the taxonomy and presenting them in groups extracting the major contributions to the specific taxonomy element. Additionally, a bridge is established between this analysis and a set of standards to also highlight the regulatory initiatives being implemented.

\subsection{Analysis via the Defined Taxonomy}

The contribution of the most significant publications to the different facets of the life cycle extension topic is hereinafter presented considering the taxonomy described in Section 2.

Literature Review. In [24], an analysis of literature reviews is performed regarding the design of Open Architecture Products (OAP) and their potential benefits to the CE concept, identifying at the same time the existing relations between product design approaches and product life extension. The major reviews in [29] specifically focus on maintenance, analyzing the methods used and the application areas in order to investigate the current standing of maintenance policy optimization issues and further explore possible improvement on a related topic. [28] deals on the historical development of the concept of circular economy and value retention options for products and materials. Three phases are distinguished in the evolution of the circular economy: Dealing with Waste, Connecting Input and Output in Strategies for Eco-Efficiency and Maximizing Value Retention in the Age of Resource Depletion, which is fully aligned with the concept of life cycle extension. The study presented in [27] is an extensive review of the indicators exploited in CE. Focusing on product life extension, the literature review performed in [19] recognizes three current lacks of research: a systematic analysis of the structure which underlies organizational efforts, the role of two businesses and consumers and a systematic study of the product lifetime extension strategies. Eventually, Ref. [25] proposes divers key research theme to classify the upgradability concept literature review: General concept and definition, Issues of upgradability, Consumer value, Remanufacturing with upgrades, Modular upgradability, Design methodology, Upgrade planning, Evaluation of upgradability, Upgradability in the context of PSS, Case studies. Ref. [31] analyzes the current literature on CE assessment and the main existing environmental assessment methodologies based on indexes. Ref. [92], through a systematic literature review considering both academic and grey literature, identified 55 sets of $\mathrm{C}$-indicators, developed by scholars, consulting companies and governmental agencies, encompassing different purposes, scopes, and potential usages. Inspired by existing taxonomies of eco-design tools and sustainability indicators, and in line with the $\mathrm{CE}$ characteristics, a classification of indicators aiming to assess, improve, monitor 
and communicate on the CE performance is proposed. The paper [30] based its taxonomy on 150 organizations identified in the academic and managerial literature engaged in extending the life of the product. Ref. [33] reviews more than two hundred papers on maintenance modeling and optimization that have appeared in the period 2001 to 2018, describes terms commonly used in the modeling process and distinguishes single-unit and multi-unit systems. The purpose of the paper [35] is to identify key upgrade-enabling design features and provide a literature review on existing PSS design methodologies with a focus on their adoption towards an upgradable PSS design framework.

Life cycle Extension. Within the taxonomy, publications that directly mention life cycle extension or indirectly consider the topic were distinguished. Directly mentioning Life cycle Extension: Refs. [24,41,58] (the ancestor publication identified during this review), Refs. [43,44,49] present LCES and methodologies; Refs. [26,46,57] deal with product life cycle extension business models; Ref. [47] proposes an end of life decision tool; Refs. [48,62] address the $\mathrm{R}$ strategies (repair, recondition, refurbish and re-manufacture); Refs. [8,20] present decision-making mechanism for EoL options; Ref. [61] develops an approach to evaluate remaining life aiming to ensure asset durability and optimize operation to extend service life. Addressing the topic in an indirect way: Refs. [28,36,52] more specifically deal with CE, but takes into account life cycle extension and its strategies as possible enablers; Refs. [37,38,40,45] deal with product and business model innovation-oriented to CE; Refs. [24,39,53] addresses product life cycle design and planning methodology; Ref. [54] explicitly introduce the concept of maintenance as a life-extension enabler, Refs. [51,60] focus on predictive maintenance, Refs. [29,58] deal with maintenance model and policy; eventually, Refs. [27,55] provide a vision on CE indicators and [63] develops a tool to improve B2B and internal communication that will enhance the maintenance life cycle.

Production Equipment. Just a few selected papers through the procedure mentioned are directly citing or addressing production equipment. Ref. [62] deals with the search of new sustainable solutions for the product lines and the improvement of products liability; Ref. [70] develops an economic repair/replacement model related to the in-use equipment; Ref. [63] studies a maintenance assistance tool of Engineering to Order manufacturing equipment.

Strategies. As suggested by [26], a part of the strategies extending production equipment life cycle is addressing the "starting loop" through the improved design of products: design for durability / reliability, design for ease of maintenance, repair, disassembly and reassembly, design for upgradability, design for modularity and part standardization, design for component recovery. A second list is related to the "slowing loop": Maintenance (including also Repair and several other kinds of maintenance activities such as the preventative and predictive), Resell-Reuse. Finally, some strategies fit in the "closing loop", involving Remanufacture, Recondition, Refurbish, Cannibalization, Recycle. The references related to the different loop areas are reported in Table 6 . Within the papers classified in this field, there are some publications (e.g., [26,38,50]), in which strategies are not the key topic of the paper and are only mentioned for information purpose or as argumentation support. Among the papers that devoted attention to strategies, papers $[25,43,46]$ are the most significant and provide key elements for the analysis and characterization of "starting loop" and "slowing loop" strategies, while [42,43] are the ones more relevant for the "closing loop" strategies. It is moreover possible to mention paper [10] as the most dated document, since it dates back to 1995, but it fully illustrates the characteristics of the strategies considered in this study. The following table, Table 5, lists the strategies identified in this study. 
Table 5. Identified strategies.

\begin{tabular}{cc}
\hline$\#$ & Strategy \\
\hline 1 & Design for durability /reliability \\
2 & Design for modularity and part standardization \\
3 & Design for ease of maintenance and repair \\
4 & Design for upgradability \\
5 & Design for disassembly and reassembly \\
6 & Resell-Reuse \\
7 & Repair or Corrective Maintenance \\
8 & Preventive maintenance \\
9 & Predictive maintenance (preventive) \\
10 & Time-based maintenance (preventive) \\
11 & Condition-based maintenance (preventive) \\
12 & Remanufacture \\
13 & Recondition \\
14 & Refurbish \\
15 & Cannibalization \\
16 & Recycle \\
&
\end{tabular}

Definition. Strategies definitions are a crucial element in order to understand how a strategy works, which are the action needed to implement it and which are the distinguishing features that allow to differentiate between the diverse approaches to life cycle extension. Table 6 in Section 4 reports a synopsis and a revision of the strategies definition to complete and clarify the existing one (when needed) together with the indication of the references related to the definitions.

Table 6. Revised definitions of LCES.

\begin{tabular}{|c|c|c|}
\hline Strategy & Revised Definition & References \\
\hline Design for durability/reliability & $\begin{array}{l}\text { The ability of a product to perform the } \\
\text { function (s) it was designed and built for } \\
\text { an extended period of time or a specified } \\
\text { period without experiencing failure or } \\
\text { excessive wear and tear, considering also } \\
\text { its environmental performances. }\end{array}$ & [26], [43], [46] \\
\hline $\begin{array}{l}\text { Design for modularity and part } \\
\text { standardization }\end{array}$ & $\begin{array}{l}\text { Design approach that is meant to achieve } \\
\text { the maximum level of simplification and } \\
\text { standardization in product design with } \\
\text { common product platform and more } \\
\text { efficient use of resources. In } \\
\text { manufacturing fields, universalization, } \\
\text { serialization and modularization are the } \\
\text { three most important metrics. }\end{array}$ & [25], [43], [68] \\
\hline $\begin{array}{l}\text { Design for ease of maintenance and } \\
\text { repair }\end{array}$ & $\begin{array}{l}\text { This approach allows the products and } \\
\text { parts to be maintained and repaired } \\
\text { easily in order to retain the functional } \\
\text { capability of a product or restore the } \\
\text { working condition of a damaged product. }\end{array}$ & [25], [30], [31], [43], [63] \\
\hline Design for upgradability & $\begin{array}{l}\text { Approach to the design meant to } \\
\text { facilitate the enhancement of a product's } \\
\text { functional as well as physical fitness for } \\
\text { ease of upgrade. }\end{array}$ & [25], [35], [43], [46] \\
\hline Design for disassembly and reassembly & $\begin{array}{l}\text { The characteristics of this approach allow } \\
\text { for the separation and reassembly of } \\
\text { products and parts in the most efficient } \\
\text { way, i.e., the most suitable sequence is } \\
\text { determined with minimal removal of } \\
\text { components, ensuring environmental } \\
\text { safety and avoiding future costly } \\
\text { environmental liabilities }\end{array}$ & [25], [34], [43] \\
\hline
\end{tabular}


Table 6. Cont.

\section{Strategy}

Design for component recovery

Resell-Reuse

Repair or Corrective Maintenance

Preventive maintenance

Predictive maintenance (preventive)

Time-based maintenance (preventive)

\section{Revised Definition}

It includes design for refurbishment and design for remanufacture. The concept of recovery stems from the fact that a certain number of parts or subassemblies have a design life that exceeds the life of the product itself, making the idea of reuse practical.

Reuse and resell can be defined as the second or further use by another consumer of a discarded product that is still in good condition and does not require any correction or repair action. The resold or reused products retain their function and identity.

Set of activities performed on a defective product so it can be used with its original function. Repair is also making a broken product operational again through fixing/replacing failed parts. The objective of repair is "bringing back to working order", "making it as good as new", "recreating its original function after minor defects", "replacing broken parts".

Preventative maintenance is the performance of inspection and/or servicing tasks that were pre-planned for accomplishment at specific points in time to retain the functional capabilities of operating equipment or systems and to reduce the probability of failure or prevent degradation of the functioning of a product.

A condition-driven preventative maintenance program. It uses direct monitoring of the mechanical condition, system efficiency, and other indicators to determine the actual mean time to failure or loss of efficiency.

A preventive maintenance consisting of restoring or replacing a component regardless of the condition of the product. This can happen based on time (predetermined time intervals) or based on the operating time of machines/components or on the remaining useful life (in this case a dedicated system is required to support data collection and maintenance planning).

\section{References}

[25], [40], [41], [42], [44], [46], [47], [49], [52], [62]

[25], [28], [30], [33], [40], [41], [42], [46], [47], [48], [49], [52]

[25], [46], [49]

[25], [46], [49] 
Table 6. Cont.

Strategy
Condition-based maintenance
(preventive)

Remanufacture

Recondition

Refurbish

Cannibalization

Recycle

\section{Revised Definition}

A strategy based on the component restoration or replacement based on a measured condition compared to a defined standard (thresholds). Condition data can then be collected through non-invasive measurements, visual inspection, performance data, and scheduled testing.

Remanufacture (or second-life production) is a strategy that implies using parts of discarded products in a new product with the same function. Used products are brought at least to original equipment manufacturer performance specification.

Remanufactured products guarantee the same quality as original products.

Remanufacture applies where the full structure of a multi-component product is disassembled, checked, cleaned and when necessary replaced or repaired in an industrial process.

Reconditioning involves taking a product and restoring all critical modules that are inspected and upgrade it to specified quality level, typically less than virgin standard. Any warranties issued are typically less than a warranty given to a virgin product.

Refurbish means restoring an old product and bringing it up to date. In general, refurbished products are upgraded and brought back to specified quality standards or satisfactory working and/or cosmetic conditions and have to fulfill extensive testing. Occasionally, refurbishing is combined with technology upgrading by replacing outdated modules and parts with technologically superior ones.

Cannibalization is the activity of recovering parts from returned products. Recovered parts are used in repair, refurbishing, reconditioning and remanufacturing of other products.

Recycling is the processing of materials to obtain the same (high-grade), or lower (low-grade), quality of recycled materials. The purpose of recycling is to reuse materials from used products and components. These materials can be reused in production of original parts if the quality of materials is high, or else in production of other parts. Recycling begins when used products and components are disassembled into parts. These parts are separated into distinct material categories. These separated materials are subsequently reused in the production of new parts.
References

[25], [46], [49]

[25], [28], [30], [40], [41], [42], [44], [46], [47], [48], [49], [52], [62]

[28], [47], [48]

[25], [28], [36], [40], [41], [42], [48], [52]

[25], [36], [41], [42]

[25], [28], [36], [40], [41], [42], [47], [49], [52], [62] 
Description and Implementation Guidelines. There is a total of 26 papers with descriptions and implementation guidelines that were further divided into three subcategories: the ones providing the description of the strategy functioning, the ones providing implementation guidelines and finally the more complete ones, presenting both these elements.

Description. After the description of the different strategies (i.e., Re-purpose, Remanufacture, Refurbish, Repair, Reuse, Refuse, Rethink, Reduce, Recycle and Recover), [40] presents a detailed analysis of them; Refs. [54,58] present in detail the global maintenance management and lifetime-extending maintenance model while [57] describes Upgrade business models. Refs. [47,48] provide reuse options description; Ref. [52] presents the stakeholder contribution in each strategy, while [25] provides a comprehensive overview of product upgradability; Ref. [45] focuses on product design strategies, while [44,46] on Product Life Extension Strategies.

Guidelines. Ref. [51] compares the maturity level of predictive maintenance 4.0 and another type of inspection and presents a list of implementation actions. The paper [50] provides an accurate decision-making mechanism for ranking the recovery strategies while [43] presents "Design for X" strategies and the related guidelines. Concerning the design approach towards remanufacturing, Refs. [71,72] present a methodology that, starting from the definition of remanufacturable product profiles, is meant to guide the design and the re-design of products in order to assure a higher level of reuse at their end of life stage; again in the context of design, Refs. $[73,74]$ outline an approach to support designers in improving the product eon of life performances in terms of disassemblability and recyclability. Ref. [61] proposed and provided an approach to evaluate remaining life aiming to ensure asset durability based on coupled digital and experimental fatigue analysis and [70] studies a repair-replacement decision model considering environmental impacts, maintenance quality, and risk. A corrective maintenance scheme for engineering equipment is developed by [65] and the paper [67] creates a flexible framework to support equipment life cycle management.

Description and Guidelines. Ref. [28] discusses the characteristics of some strategies such as Resell, Reuse, Re-manufacture, Repair, Refurbish and Recycle and some actions that make the implementation of the strategy possible. Ref. [47] describes product recovery strategies together with an indication to direct a product towards the appropriate strategy based on the problem. In [42], the product recovery strategies are described with the actions that must be implemented to extend products life cycle, while [49] analyzes the LCES and the product characteristics after the implementation of the strategy, the information related to the actions implemented and the characteristics that link the strategies and the production phases. Ref. [31] proposes a reference framework for the monitoring phase of a CE strategy and a systematic approach for the choice of the adequate methodology, Ref. [63] develops an application that is moving towards digitalization, while the paper [66] studies a replacement decision framework based on the influencing factors and motivations behind equipment replacement. Ref. [35] is committed to elaborate a framework to design upgradable product-service systems.

Metrics and Evaluation Methodologies. In this area, literature findings were divided into two sub-groups: Methods and Tools for decision making and Metrics. The investigated papers propose a plethora of evaluation methodologies, instruments and indicators for the analytical assessment of product performances that are pondered on different perspectives, ranging from the technical to the sustainability ones. Most of the publication indeed focus on the evaluation of economic and environmental performances, that, as also stated by [93], results as a crucial element in the decision-making process.

Methods and Tools for decision making. Refs. [71,72], describe a tool to assess how much a product can be remanufactured starting from its design phase, while [73,74] outline a methodology composed of four indices and a tool to assess the possibilities to disassemble and recycle a product at the end of its life span in order to improve its performances concerning these aspects. Ref. [36] proposes a general product recovery multi-criteria 
decision tool to evaluate product circularity strategies under several, often-conflicting criteria, to assess the feasibility of recovery options with respect to relevant business, legal, environmental, social and economic factors and by taking into account the preferences of the decision-maker. Decision-making factors are also identified in regard to technical, economic, business, environmental and societal aspects. Similarly, Ref. [58] reports the development of a tool to aid designers in planning recovery cycles for a product at the end of its working life supported by a calculation model that calculates an indicator that translates the environmental effects of recovery cycles in terms of extension of the product's useful life. The product Life Cycle Planning (LCP) methodology accompanied by a design support tool is presented in [53]. The methodology clarifies the medium or long-term production and collection plan for the product family, then target values for the product and its life cycle are set to develop eco-solution ideas, realizing reasonable resource circulation by using various life cycle option analysis charts; eventually, the eco-design concept is evaluated at the beginning of the life of the product. Supporting the methodology, the design tool was conceived to efficiently planning product life cycles by using quality function deployment and life cycle assessment data. On the contrary, the study performed in [47] presents a tool that starts from a different perspective: a method to quickly and accurately determine the status of a product that has already undergone an end-of-life recovery strategy. The tool assures to rapidly identify the status of a product, to quickly determine the best terminology for end-of-life products that have received a recovery treatment, a reliable method to check whether a re-manufactured product is wrongly labeled as "something else", a way to ensure compliance with legislation and standards, and the identification of only the essential characteristics of a re-manufactured product. The purpose of [50] is to provide a decision-making method on selecting the most sustainable and suitable EOL product recovery option considering, unlike other available methodologies, all the interests of the stakeholder involved in the product life cycle. Eventually, considering nine different modes of product life extension, Ref. [49] provides a framework and a qualitative evaluation methodology to determine what issues, resource requirements and management capabilities are required for specific life extension modes. This framework provides guidance to practitioners and academics on commonalities between different product life extension modes, thereby assisting practitioners in leveraging current internal skills and capabilities and researchers in determining the generalizability of research. The paper [32] introduces some troubleshooting and life-predicting techniques and approaches, while [75] paper proposes a new degradation modeling and RUL (Remaining Useful Life) estimation method taking the influence of imperfect maintenance activities on both the degradation level and the degradation rate into account. Ref. [64] builds a new data-driven model based on Long Short-Term Memory Recurrent Neural Networks algorithm used to detect the degradation of a manufacturing system and predict its future health condition. A risk-based maintenance tool able to reduce the probability of failure of equipment and the consequences of failure is develop by [94] and some techniques and methodologies to adopt during the risk analysis phase are detailed and structured. The paper [34] presents recent methods for modeling and process planning in disassembly and the applications to industrial products.

Metrics. Concerning metrics, Ref. [95] proposes a concept of methodological recommendations for estimating service life for designing, fabricating, and appraising safety of industrial equipment. The concept solves the problem of estimating the full residual calculated service life of industrial equipment. Focusing on two specific strategies (maintenance and predictive maintenance), Ref. [60] provides a model to determine the economic cost and benefits to introduce IoT in predictive maintenance, testing the model on different scenarios, while [29], an evaluation of maintenance policy optimization through different models (e.g., Mathematically based model, Simulation-based model, Artificial intelligencebased model). On the contrary, Ref. [55] provides a wider vision on CE indicator, proposing a classification framework to categorize indicators on CE strategies, grouped according to their attempt to preserve functions, products, components, materials, or embodied energy 
and considering different measurement scopes on environmental, social, or economic dimensions. Again, concerning CE, Ref. [27] aims to develop a set of indicators linking CE principles, Circular Business Model and the pillars of Sustainability, developing a group of indicators focused on the three dimensions of Sustainability (environmental-from the material perspective-economic and social), applied in Circular Business Models to capture the innovations brought by CE that conventional indicators do not measure. Eventually, Ref. [48] proposes a hierarchy of reuse options that allows evaluating the relationship between the life extension strategy and: warranty, work content, performance, energy and cost. This approach could suggest possible metrics to evaluate, in a qualitative way, the benefits and the required "engagement" in implementing a specific reuse option. Ref. [68] cites universalization, serialization and modularization as the three important metrics in the standardization of manufacturing. To evaluate and optimize the standardized procedures, some metrics were designed among with a quantitative analysis-based evaluation model of equipment system. Ref. [69] proposes a single generic indicator based on durability and environmental footprint for material selection. This indicator integrates into a single calculation chemical and mechanical durability, together with environmental impacts associated with the material.

Business Models. Ref. [57] describes and compares four generic types of upgrade business models based on industrial cluster cases related to product life extension. Using a modified business model canvas approach, the four upgrade business models are compared concerning how they create value for the customers, how they organize their main activities and how they earn money. The study performed in [26] develops and empirically validates a methodology to classify product lifetime extension business models, involving organizations and consumers, to bring quantitative rigor to the conduct and presentation of taxonomy research in the field of the circular economy. Ref. [25] reviews a series of publications dealing with Business models for upgradable products, while [30] offers a framework and a taxonomy based on product lifetime extension business models and [45] list a series of circular business model strategies. Concerning life cycle extension, this publication describes Business model strategies for slowing loops such as Extending product value (Exploiting the residual value of products-from manufacture, to consumers, and then back to manufacturing-or collection of products between distinct business entities), Classic long-life models (Business models focused on delivering long-product life, supported by design for durability and repair) and Encourage sufficiency (solutions that actively seek to reduce end-user consumption through principles such as durability, upgradability, service, warranties and reparability and a non-consumerist approach to marketing and sales). Specifically focusing on product life extension, Ref. [46] explores the topic in a business context and the associated consequences for product design. In this paper a starting point is provided for this exploration, by outlining the development of a business model framework for product life extension, using strategies for product life extension and mapping these against common elements of contemporary business model theory.

Digitalization and Lifetime Extension. From the analysis of the main trend about how digitalization affects the product lifetime and the extension of machinery and equipment, 21 papers were selected. The possible role of digitalization on the sustainability concept was already investigated by [96], even though more focalizing on sustainability assessment and optimization of environmental performances. The literature review here presented is on the contrary more focused on its role for $\mathrm{CE}$ and life cycle extension. The papers were gathered according to the following goals: literature review, case studies, theoretical analysis, survey and taxonomy.

Literature review papers. A list of seven papers was retrieved from the literature that is meant to describe how digitalization can play a crucial role to enable a more sustainable circular economy taking into account smart manufacturing, product design and I4.0. In particular, Ref. [76] takes into account how smart enablers that involve physical and digital components permits to add value to the products, extending the product lifetime. Refs. $[77,78]$ highlight the smart manufacturing issues, in particular, about how product's 
lifetime is extended by predictive, preventive or reactive maintenance. Refs. [45,79] focus on how digitalization affects lifetime extension, in particular, utilizing digital technologies such as AI, IoT or Blockchain enhances the ways in developing and improving transparency and traceability throughout the product lifetime. Ref. [80] is related to the product design in combining localized smart design and manufacturing approach for manufacturing computer equipment. Ref. [80] describes how smart products and digital tools enable better performance monitoring, data-driven design, and an extension of the product life cycle. Ref. [82] provides a literature review and critical analysis of existing research into DT applications, with a view to identifying the opportunities for research and applications in the construction domain. Ref. [83] reviews the current state-of-the-art of all aspects of condition monitoring for medium voltage switchgear and presents an approach to develop a predictive maintenance system based on novel sensors and machine learning. The interest of operators of electrical equipment and machinery in condition monitoring and predictive maintenance is due to the avoidance of catastrophic failures, the reduction of operational cost, and the lifetime extension of the equipment.

Case study papers. Ref. [84] presents a case study of LED lighting where the role of IoT is relevant to enable monitoring and predictive maintenance, to improve the estimation of the remaining lifetime of used products and inform design decisions to improve the durability of products. Refs. $[85,86]$ are focused on lifecycle management where sustainable manufacturing, IoT and sensor information can be utilized to promote lifetime extension in the personal computer and for automobile, aircraft and ship manufacturers, respectively. The role of the digital twin for prediction, integration of the life cycle of a product and develop a model to extend the lifetime is described in the case study of existing marine structures [87], rotating machinery fault diagnosis [89] and wind turbine [90]. Ref. [88] forecasts the residual life of an assembly unit or machinery making maintenance planning more effective and preventing the occurrence of emergency failures for the vibration-based diagnostic. Eventually, no specific case studies were retrieved on production equipment.

Theoretical papers. Ref. [91] describes the benefits of increasing the product lifetime and how globalization trend is not technical and economically favorable if a country wants to promote lifetime extension of products. On the other side, Ref. [92] investigates how digital technologies (e.g., IoT, BigData, analytics) functionalities affect $\mathrm{CE}$ value drivers increasing resource efficiency and extending lifespan; it moreover introduces an approach for highlighting the conceptual framework in table referring to some $\mathrm{CE}$ value drivers showing which references of the analyzed literature are referred to the lifespan extension of a product.

Survey papers. Ref. [10] provides a survey about how digitalization can play a crucial role to enable more sustainability and enables more efficient processes in companies, helping minimize waste, promoting longer life for products.

Taxonomy papers. Finally, papers offering a taxonomy of product lifetime extension (PLE) as a field of study through the development of a framework of product lifetime extension business models (PLEBM) are Refs. [26,30]. Ref. [30] shows product lifetime extension business models and strategies in the literature where the digital interactive platform and digital transactional provide information or live support on the extension of product lifetime and provide the opportunity to conduct or schedule the exchange of the product whose lifetime is to be extended. Ref. [26] develops and empirically validates a methodology to classify a specific type of circular business model, namely product lifetime extension business models, involving organizations and consumers, to bring quantitative rigor to conduct and presentation of taxonomy research in the field of the circular economy.

\subsection{Maintenance and Remanufacturing Standards}

As previously seen, with the introduction of digitalization and other important key strategies, the topic of lifetime extension framed into Circular Economy has gained relevance and impact in today's' manufacturing environments. However, not only academic publications and patents are responsible for this new impact, but also the end results that 
most of these have. One important outcome is the standardization procedures that help manufacturing companies to implement and maintain the best practices in terms of, e.g., safety and process optimization, both internally and also among companies. Standardization foster the alignment of companies thought the value chain in terms of procedures, product specification and quality that increases the trustworthiness in both B2C and B2B commercial transactions.

Taking again the example of Resell/Reuse in the introduction Section, performing a set of procedures for the collection of maintenance logs, machine parameters, product quality and degradation data enables the calculation of the machine's current health and predict its performance in the future.

This way, the trustworthiness is increased and the servitization (e.g., leasing) towards machine resell can be achieved because the end customer has all the information about the machine's lifetime.

Based on this, there are a set of existing standards already targeting some of these procedures. The following presented standards focus on two main topics: (1) maintenance procedures and predictive maintenance, together with (2) specifications and design for remanufacturing. As a sneak-peek of each topic, eight standards about maintenance and five about remanufacturing are presented.

Regarding maintenance, the "CWA 17492:2020-Predictive control and maintenance of data in- tensive industrial processes" is a standard focusing on predictive maintenance and defines machine learning / deep learning techniques for predicting process and equipment drifts, hence providing indications on when to perform maintenance and machines health state.

"EN 15341:2019-Maintenance-Maintenance Key Performance Indicators" defines a set of key performance indicators to quantify and increase the effectiveness, efficiency and sustainability in the process of maintenance actions for physical assets.

"prEN 17485-Maintenance-Maintenance within physical asset management-Framework for improving the value of the physical assets through their whole life cycle" and "EN 16646:2015-Maintenance-Maintenance within physical asset management" introduce the physical asset management and address the role and importance of maintenance within physical asset management system during the whole life cycle of an item.

"EN 17007:2018-Maintenance process and associated indicator" illustrates for the maintenance process all the characteristics and steps of the defined processes, together with the establishment of a maintenance model that gives guidelines for defining indicators. This is a key element in order to standardize the whole maintenance process and therefore make all the maintained equipment comparable among themselves and lifetime extension strategies can ultimately be more precise in their analysis.

"EN 13269:2016-Maintenance-Guideline on the preparation of maintenance contracts" and "EN 13306:2018-Maintenance-Maintenance terminology" and "EN 13460:2009Maintenance-Documentation for maintenance" This set of three standards focus on the maintenance contracts to be established, the terminology used and documentation. This is particularly important because these standards define at a business level how maintenance is performed and is understood. Contracts are based on well-established terminology and documentation that govern the maintenance process and should include lifetime extension strategies based on maintenance actions, or even others like KPIs and data-based analysis throughout its lifetime.

As for the remanufacturing standards, the "ANSI RIC001.1-2016-Specifications For The Process Of Remanufacturing" is a standard that works on the definition of remanufacturing and clearly separates it from other practices. It also provides a benchmark, specification and characterization for the process of remanufacturing.

"ISO 8887-1:2017-Technical product documentation-Design for manufacturing, assembling, disassembling and end-of-life processing-Part 1: General concepts and requirements" standard specifies the requirements for the preparation, content and structure of Technical Product Documentation (TPD) of design output for the cycles of manufacturing, 
assembling, disassembling and end-of-life processing of products. This is particularly interesting because lifetime extension strategies can be incorporated in TPD and make sure equipment is handled towards its extension.

There also some standards that can be oriented towards remanufacturing or extending equipment capabilities based on well-defined specifications and processes. Such an example is the "ISO 9409-1:2004-Manipulating industrial robots-Mechanical interfaces-Part 1: Plates" and "ISO 9409-2:2002-Manipulating industrial robots-Mechanical interfacesPart 2: Shafts" that focus on the mechanical aspects and remanufacturing procedures can be proposed as an extension. By knowing how to manipulate such mechanical interfaces and considering that industrial robots are key in what concerns flexibility and process adaptability, it is possible to redesign such products for new purposes and promptly use them for new tasks.

"ISO/TR 16355-8:2020-Applications of statistical and related methods to new technology and product development process-Part 8: Guidelines for commercialization and life cycle" This describes after optimization of product design to address non-functional requirements, for example, test, produce, commercialize, deliver, support, and eventually retire a product from the market and provides guidance on the use of the applicable tools and methods. Based on these non-functional requirements, the concept of remanufacturing can be introduced in all of them. For example, the testing and commercialization of remanufacturing processes can be contemplated, since new technology can result from extending the capabilities in machines.

The analysis of the literature performed via the proposed taxonomy and the research carried out also on standard is providing several topics of discussion that could guide future literature investigations and provide useful hints for the actual integration of the life cycle extension concept in industrial practices. This dissertation is proposed in the following section of this work.

\section{Discussion}

Concerning the application of strategies in industries, the analysis of the selected literature performed in the previous section highlights various open issues to be treated both in the industrial and academic debates. The discussion is thus structured into two main blocks. The first one is a proactive approach that is meant to re-elaborate literature findings on strategy definitions and proposing a framework for future works in the field of LCSE. The last part of the discussion is then dedicated to sketch possible future areas of literature investigation in the field addressed by this work.

\subsection{Life Cycle Extension Strategies and Definitions}

The first literature evidence concerns the fact that strategy definitions are not well established or at least acknowledged, leading to an unclear application and paving the way to misunderstandings. For that reason, a dedicated subsection is introduced where the list of the strategies gathered thanks to the literature analysis is retrieved and completed with updated definitions obtained starting from the ones available in the literature. A certain confusion emerged from the work carried out on the strategies definitions since most of them are unclear, incomplete or even conflicting. In the case of design-related strategies of the "starting loop", some repetitions were detected together with the need to slightly revise the formulation of the descriptive sentences that, in general already had a proper state. Concerning the "slowing loop" area, the material available in literature on maintenance already was in a good shape, thus the revision analysis only focused on the identification of the maintenance activities related to product life extension. On the contrary, the work on the "closing loop" strategies revealed to be more challenging since the existence of several definitions for the same strategy that sometimes introduces overlaps and conflict. In this area, the revision activities thus focused on defining homogenized and coherent definitions in order to make them clear and unambiguous. Table 5 reported hereinafter resume the activities performed on the LCES definitions. 


\subsection{The Strategy Characterization Framework}

An additional focal point for the actual application in industries of product life cycle extension concept is the need for a framework that is meant to provide a deeper and structured analysis on strategies. The objective of the Strategy Characterization Framework (SCF) here presented is to better characterize the LCES, putting the basis for future works that will produce methodologies for the selection of the best strategy to be applied for production equipment life cycle extension on different specific industrial cases. As a consequence of the triplet analysis about scientific papers, patents and standards, an initial proposal for a possible future standardization procedure was an organic step. Industrial practice needs more detailed information about how a strategy works, how it can be put in place, which are the actors involved in its implementation and which are the costs and the benefits offered from the sustainability point of view, mainly focusing on economic and environmental aspects. In order to detect this information from the strategy analysis, a Strategy Characterization Framework (SCF) was conceived as a possible solution for the detailed characterization of the LCES. The SCF is constituted by a list of fields that are meant to better typify the strategies used. The description of the fields is hereinafter reported.

- Target: it reports which is the focus of the strategy. Specifically, a strategy may concern the whole equipment or parts of it such as assemblies, components or the materials constituting the product.

- Life cycle phases involved: it considers the possible life cycle phase of the production equipment that are affected/involved by the strategy. As already shown, LCES are not only affecting the EoL phase of the equipment but could require intervention in many other product life span moments, starting from the design phase.

- Stakeholder involved: it is meant to list the stakeholders mainly involved in the strategy implementation. This field of the SCF is meant to provide a view on the different actors that are actively or passively involved in the LCES, both in its implementation and during the functioning of the strategy.

- Stakeholder contribution: it describes for each stakeholder their contribution to the strategy implementation and functioning. After identifying the involved partners, their specific role, active or more passive, has to be precisely recognized so that the Original Equipment Manufacturers have a map to know how and when a stakeholder has to be activated or addressed.

- Hierarchy: it identifies the hierarchy distinguishing short loop (where product remains close to the user and its original function), medium-long loop (where products are upgraded and, at least a part of them, may be moved away from their first installation place) and long loop (where products lose their original function or components are mainly exploited as monitored sources of materials). This field offers a rapid, qualitative overview on how much the strategy is oriented to a strict application of the CE approach, where the short loop strategies are the ones aimed to prolong the life cycle of the equipment as a whole, with few interventions and new components needed.

- Ownership model: it indicates the owner of the machinery after the execution of the actions related to a given strategy. The field is meant to distinguish strategies based on a more traditional business model, where the ownership is retained by the equipment user, to the ones that are promoting servitization, where the ownership of the machine is maintained by the OEM.

- Equipment condition after the implementation of the strategy: it indicates the state of the equipment after the application of a certain strategy. The condition of the product can correspond to: the original one, a decreased quality of the whole machine and their components, enhanced performances or even a completely different function for the machine subjected to the strategy implementation. 
- Enabling elements/technologies: it shows the elements that enable the strategy deployment. Many LCES requires the deployment of technologies (IoT, augmented and virtual reality, recycling technologies...) and/or methodologies (design for remanufacturing, pay per use approach) in order to actually put in place the strategy in a specific industrial application.

- Closing loop management model: it indicates the life cycle loop management approach promoted by the strategy. In the context of CE and LCES it is improper to talk about End of Life of the equipment or of its components, even though during life cycle extension some parts are discharged. The closing loop management model can thus assume a unique approach ( $100 \%$ reuse) or a blended one ( $70 \%$ reuse, $30 \%$ recycle for unrecovered parts).

- Circular BM involved: this field is meant to identify which are the possible Circular Business Models related to the strategy application. This is a focal point in order to make companies understand how life cycle extension can generate profit.

- Strategy Implementation Actions: it lists the action needed to implement a strategy starting from the blank page. This field of the SCF is meant to provide valuable support to companies interested in the actual implementation of LCES since they could exploit the list checking their as-is status, evaluating their maturity level in respect of a specific methodology and plan next steps and concrete activities in order to put in place the desired approach to equipment life cycle extension.

An example of the SCF application is reported in Table 7.

Table 7. Application of the Strategy Characterization Framework (SCF) to the Resell-Reuse strategy.

\begin{tabular}{|c|c|}
\hline Field & Resell-Reuse Strategy \\
\hline Revised definition & $\begin{array}{l}\text { Reuse and resell can be defined as the second or further use by } \\
\text { another consumer of a discarded product that is still in good } \\
\text { condition and does not require any correction or repair action. } \\
\text { The resold or reused products retain their function and identity. }\end{array}$ \\
\hline Typology of strategy & Closing loop \\
\hline Target & Equipment \\
\hline Stakeholder involved & $\begin{array}{c}\text { 1. Customer } \\
\text { 2. Retailer } \\
\text { 3. OEM or an alternative one } \\
\text { 4. Reverse logistic partners } \\
\text { 1. Buying second hand, or }\end{array}$ \\
\hline Stakeholder contribution & $\begin{array}{l}\text { 1. Sell equipment that was not or hardly in use, after some } \\
\text { cleaning or minor adaptations restoration; } \\
\text { 2. Resell used equipment with quality inspections, cleaning and } \\
\text { small repairs; } \\
\text { 2. Resell of unsold returns or products with damaged } \\
\text { packaging; } \\
\text { 2. Multiple re-uses of (transport) packaging; } \\
\text { 3. Collect and resell used equipment; } \\
\text { 4. Collection of used equipment and delivery to the new owner. }\end{array}$ \\
\hline Lifecycle phases involved & EoL/Retailing \\
\hline Hierarchy & Short loop \\
\hline Ownership model & OEM / Consumer (depending on the related BM) \\
\hline Equipment condition after the implementation of the strategy & Original \\
\hline Enabling elements / technologies & $\begin{array}{l}\text { Sharing platforms (online consumer-to-consumer auctions for } \\
\text { used products) }\end{array}$ \\
\hline $\begin{array}{l}\text { Closing loop management model } \\
\text { Circular BM involved }\end{array}$ & $\begin{array}{c}\text { Oriented to extend original equipment lifecycle } \rightarrow \text { Reuse } 100 \% \\
\text { Lifespan extension }\end{array}$ \\
\hline
\end{tabular}


Table 7. Cont.

Field

Strategy implementation actions

\section{Resell-Reuse Strategy \\ Design phase:}

Modular design that allows the upgrade of critical components or assemblies or the replacement of components subject to wear;

Plan to make some components available for a long time. Manufacturing phase:

Flexible internal production process (to guarantee the spare parts production);

Flexible purchasing process to guarantee the acquisition of the spare parts;

Repair the damaged components and reuse them. Logistic phase:

Organize reverse logistics of out of date or damaged components;

Organize the distribution of the updated components or spare parts.

Equipment operation phase:

Introduction of IoT devices to monitor the working conditions of critical components;

Introduction of monitoring systems and decision support tools (automated) related to the IoT devices. Maintenance phase:

Introduction of maintenance services able to replace worn components and upgrade machinery;

User of monitoring systems. It may decide to introduce IoT

devices and create monitor systems. It may decide to change some pieces.

End of "first" Life phase:

See reverse logistic in the Logistic process phase;

Repairable / Reusable Component: Repair and reuse in different equipment;

Waste components: send them for recycling;

Dispose of damaged spare parts.

The SCF acts as a basis for the forthcoming research activities in this domain. The next steps could concern the refinement of this framework, with the addition or the modification of the proposed fields, together with its actual exploitation, that is, the completion of the field for each of the strategy interesting for the production equipment application.

\subsection{Recommendation for Future Literature Investigations}

This final part of the discussion is dedicated to the identification of possible future areas of literature investigation that is: the absence of literature dedicated to CE applied to industrial equipment; the need for CE indicators mainly focusing on life cycle extension strategies benefits on environmental and economic areas of sustainability; digitalization of manufacturing as an enabler of resource preservation. Literature analysis previously presented shows how production equipment is scarcely treated in CE related literature, despite the high potential in resource-saving related to their lifespan expansion. More focused investigations are needed in order to address the specific needs of manufacturing machines from the business, the technical and the environmental benefits point of view. Moreover, indicators for the economic and environmental evaluation of life cycle extension strategies are needed to recognize the most effective and efficient strategy to be applied in specific industrial cases. The environmental indicators have to provide industries the certainty that the applied strategy generates fewer impacts all along the product life cycle, avoiding shifting the problem from a phase to another or from one compartment to a different one. Through comparison, the calculation of LCA-oriented indicators is assuring that the selected strategy shows less impact than the traditional model based on extractconsume-throw away; quantitative measurement moreover allows to ponder which of 
the LCES is more ecological for a specific industrial case. Similarly, also the economic evaluation has to provide a life cycle-oriented vision to assure that all the costs generated are monitored. Together with the cost monitoring, the generation of revenues assumes a crucial role in order to assess how the applied strategy is meant to generate profit for the OEM, guaranteeing the economic viability of the new business model introduced. Additionally, in this case, the indicators developed could be exploited to compare an LCES with the linear economy model or to assess which is the more profitable strategy to be applied. Eventually, digitalization of manufacturing is an emerging topic that could potentially support, or indeed enable, the translation of the life-extension concept into industrial practices. In this context, an analysis was carried out on patents related to each LCES identified in this paper by Table 5, focusing on how the digitalization trend is affecting such strategies and what are the market trends of digitalization in circular innovations (Figure 8). Indeed, on the one side, digitalization can enable circular economy innovation by connecting data, partners, devices and customers in individual parts of the value chain. On the other side, digital transformation can be an opportunity for companies to re-think their future, strategy, value chain and value creation. As the figure highlights, digitalization shows high relevance mainly with predictive and preventative maintenance, design for reliability-durability-disassembly and resell, while low relevance for recycle, remanufacturing and reuse. Future literature work could be focused on the application of digitalization on these strategies, starting from the theoretical and methodology point of view and then providing valuable applications in industrial use cases.

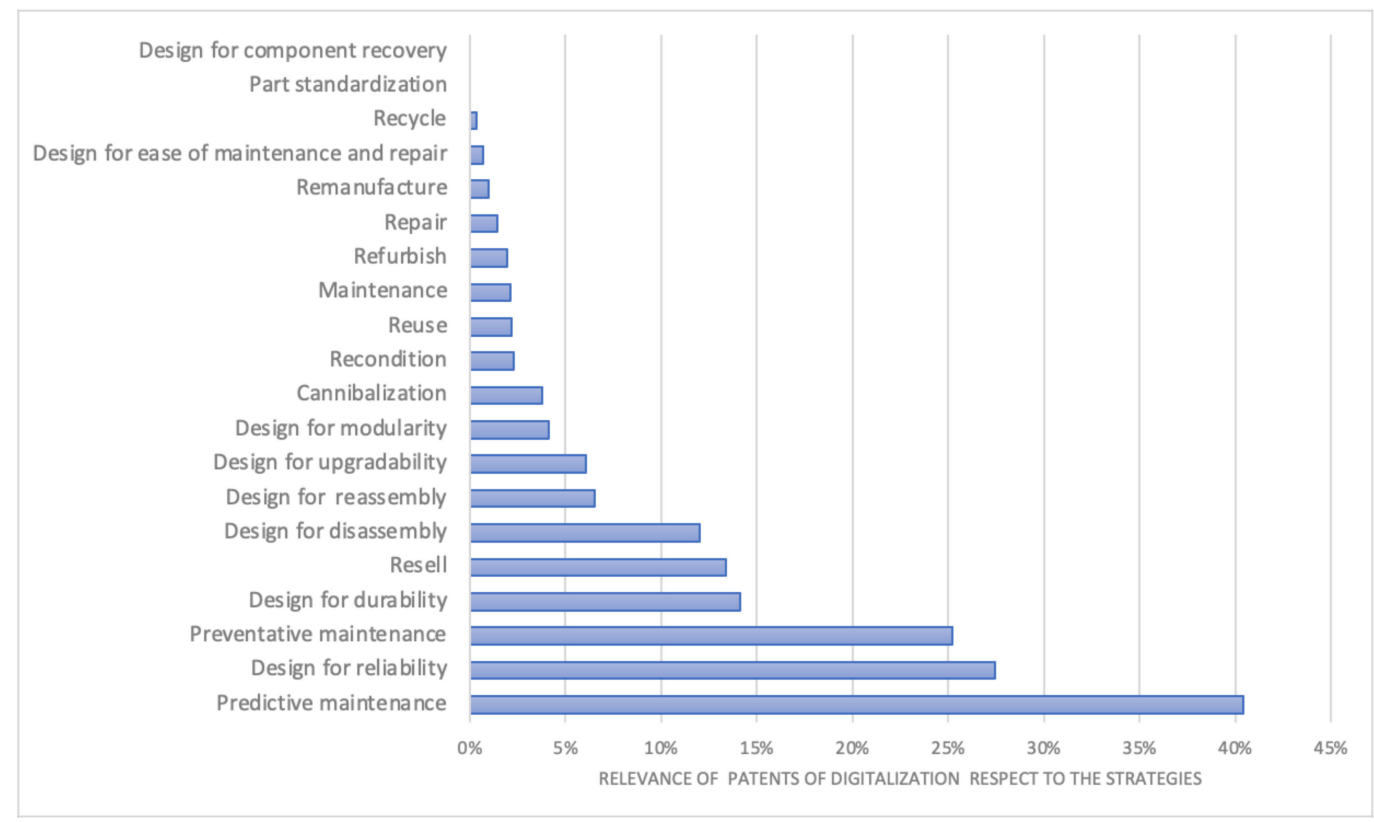

Figure 8. Relevance between digitalization patents and strategies of Table 5 .

\section{Conclusions}

As the main conclusion of this study, first, it was observed that the topic of $C E$ is very wide and diverse, with a high number of research directions, from environmental impact to artificial intelligence techniques for a more informed and wise decision regarding existing equipment. Thus, a better characterization of all these fronts is attempted in the present paper, giving clear and objective definitions so one could rely upon them when studying each topic and better frame its own research development.

Secondly, in the proposed strategies related to well-established areas, such as predictive and preventive maintenance in the "slowing loop", more application scenarios that explain direct economic and environmental benefits, together with a flexible and well-establish methodology for practical implementation. For this aspect, the Strategy 
Characterization Framework is proposed, where the main goal is to provide companies with a list of fields to describe how the strategy was implemented and what was observed afterward. By describing these fields throughout the strategy implementation, more consistent evidence will be recorded mainly for reproducibility and replication purposes in other industries.

Last but not least, the third conclusion is related to both paper and patent trends that indicate strong growth in the last 5 years, representing an increasing awareness for this topic and ultimately the development of a large number of strategies and methods for this research area. It is often observed that a certain area that is rapidly growing becomes quickly inconsistent, with conflicting concepts due to the diverse amount of new innovative ideas that do not gain their own place. Thus, this review additionally serves to pack up this field of CE and LCES through a revised taxonomy, matching with relevant papers, so that new strategies and methods can be placed in their deserved place.

Funding: This research was funded by European Union's Horizon 2020 research and innovation programme under grant agreement No 869884.

Institutional Review Board Statement: Not applicable since the study is not involving humans or animals.

Informed Consent Statement: Not applicable since the study is not involving humans.

Data Availability Statement: Data sharing not applicable.

Acknowledgments: The work presented here was part of the project "RECLAIM- RE-manufaCturing and Refurbishment LArge Industrial equipMent" and received funding from the European Union's Horizon 2020 research and innovation programme under grant agreement No 869884.

Conflicts of Interest: The authors declare no conflict of interest.

\section{References}

1. Milios, L. Advancing to a Circular Economy: Three essential ingredients for a comprehensive policy mix. Sustain. Sci. 2018, 13, 861-878. [CrossRef]

2. Ellen MacArthur Foundation. Available online: https://www.ellenmacarthurfoundation.org/assets/downloads/schoolscolleges/Schools-Colleges-WLL-Lesson-Plan-3-F.pdf-page5 (accessed on 15 December 2020).

3. Korhonen, J.; Honkasalo, A.; Seppälä, J. Circular Economy: The Concept and its Limitations. Ecol. Econ. 2018, 143, 37-46. [CrossRef]

4. Mihelcic, J.R.; Crittenden, J.C.; Small, M.J.; Shonnard, D.R.; Hokanson, D.R.; Zhang, Q.; Chen, H.; Sorby, S.A.; James, V.U.; Sutherland, J.W.; et al. Sustainability Science and Engineering: The Emergence of a New Metadiscipline. Environ. Sci. Technol. 2003, 37, 5314-5324. [CrossRef] [PubMed]

5. Directorate-General for Communication (European Commission). Circular Economy Action Plan - For a Cleaner and More Competitive Europe; EU publications: Brussels, Belgium, 2020; Available online: https://ec.europa.eu/jrc/communities/en/community/cityscience-initiative/document/circular-economy-action-plan-cleaner-and-more-competitive (accessed on 15 December 2020).

6. Planing, P. Towards a circular economy-How business model innovation will help to make the shift. Int. J. Bus. Glob. 2018, 20, 71. [CrossRef]

7. Bressanelli, G.; Perona, M.; Saccani, N. Challenges in supply chain redesign for the Circular Economy: A literature review and a multiple case study. Int. J. Prod. Res. 2019, 57, 7395-7422. [CrossRef]

8. Rajput, S.; Singh, S.P. Industry 4.0—Challenges to implement circular economy. Benchmarking Int. J. 2019. [CrossRef]

9. Hopkinson, P.; Zils, M.; Hawkins, P.; Roper, S. Managing a Complex Global Circular Economy Business Model: Opportunities and Challenges. Calif. Manag. Rev. 2018, 60,71-94. [CrossRef]

10. Antikainen, M.; Uusitalo, T.; Kivikytö-Reponen, P. Digitalisation as an Enabler of Circular Economy. Procedia CIRP 2018, 73, 45-49. [CrossRef]

11. Neligan, A. Digitalisation as Enabler Towards a Sustainable Circular Economy in Germany. Intereconomics 2018, 53, 101-106. [CrossRef]

12. Sarc, R.; Curtis, A.; Kandlbauer, L.; Khodier, K.; Lorber, K.E.; Pomberger, R. Digitalisation and intelligent robotics in value chain of circular economy oriented waste management-A review. Waste Manag. 2019, 95, 476-492. [CrossRef]

13. Demestichas, K.; Daskalakis, E. Information and Communication Technology Solutions for the Circular Economy. Sustainability 2020, 12, 7272. [CrossRef]

14. Rosa, P.; Sassanelli, C.; Urbinati, A.; Chiaroni, D.; Terzi, S. Assessing Relations Between Circular Economy and Industry 4.0: A Systematic Literature Review. Int. J. Prod. Res. 2019, 58, 1662-1687. [CrossRef] 
15. Bressanelli, G.; Adrodegari, F.; Perona, M.; Saccani, N. Exploring how usage-focused business models enable circular economy through digital technologies. Sustainability 2018, 10, 639. [CrossRef]

16. Prisma Statement, Flow diagram and Checklist. 2009. Available online: http://prisma-statement.org/ (accessed on 15 December 2020).

17. Pullin, A.S.; Stewart, G.B. Guidelines for systematic review in conservation and environmental management. Conserv. Biol. 2006, 20, 1647-1656. [CrossRef] [PubMed]

18. Chakraborty, A.; Stewart, G. Strategy taxonomy and classification system development-Study of two state governments. In Proceedings of the 2012 IEEE International Conference on Management of Innovation \& Technology (ICMIT), Sanur Bali, Indonesia, 11-13 June 2012; pp. 140-145.

19. Chrisman, J.J.; Hofer, C.W.; Boulton, W.R. Toward a System for Classifying Business Strategies. Acad. Manag. Rev. 1988, 13, 413. [CrossRef]

20. Tasleem, M.; Khan, N.; Shah, S.T.H.; Saleem, M.; Nisar, A. Six steps implementation framework for corporate sustainability performance management. RISUS J. Innov. Sustain. 2017, 8, 3. [CrossRef]

21. Nawaz, W.; Koç, M. Development of a systematic framework for sustainability management of organizations. J. Clean. Prod. 2018, 171, 1255-1274. [CrossRef]

22. Gallotta, B.; Garza-Reyes, J.A.; Anosike, T.; Lim, M.K.; Roberts, I. A conceptual framework for the implementation of sustainability business processes. In Proceedings of the 27th Production and Operations Management Society (POMS), Orlando, FL, USA, 6-8 May 2016.

23. Chofreh, A.G.; Goni, F.A. Review of Frameworks for Sustainability Implementation. Sustain. Dev. 2017, 25, 180-188. [CrossRef]

24. Mesa, J.A.; Esparragoza, I.; Maury, H. Trends and Perspectives of Sustainable Product Design for Open Architecture Products: Facing the Circular Economy Model. Int. J. Precis. Eng. Manuf. Green Technol. 2019, 6, 377-391. [CrossRef]

25. Khan, M.A.; Mittal, S.; West, S.; Wuest, T. Review on upgradability-A product lifetime extension strategy in the context of product service systems. J. Clean. Prod. 2018, 204, 1154-1168. [CrossRef]

26. Ertz, M.; Leblanc-Proulx, S.; Sarigöllü, E.; Morin, V. Advancing quantitative rigor in the circular economy literature: New methodology for product lifetime extension business models. Resour. Conserv. Recycl. 2019, 150, 104437. [CrossRef]

27. Rossi, E.; Bertassini, A.C.; dos Santos Ferreira, C.; Neves do Amaral, W.A.; Ometto, A.R. Circular economy indicators for organizations considering sustainability and business models: Plastic, textile and electro-electronic cases. J. Clean. Prod. 2020, 247, 119137. [CrossRef]

28. Reike, D.; Vermeulen, W.J.V.; Witjes, S. The circular economy: New or Refurbished as CE 3.0?-Exploring Controversies in the Conceptualization of the Circular Economy through a Focus on History and Resource Value Retention Options. Resour. Conserv. Recycl. 2018, 135, 246-264. [CrossRef]

29. Ding, S.H.; Kamaruddin, S. Maintenance policy optimization-Literature review and directions. Int. J. Adv. Manuf. Technol. 2014, 76, 1263-1283. [CrossRef]

30. Ertz, M.; Leblanc-Proulx, S.; Sarigöllü, E.; Morin, V. Made to break? A taxonomy of business models on product lifetime extension. J. Clean. Prod. 2019, 234, 867-880. [CrossRef]

31. Elia, V.; Gnoni, M.G.; Tornese, F. Measuring circular economy strategies through index methods: A critical analysis. J. Clean. Prod. 2017, 142, 2741-2751. [CrossRef]

32. Hu, C.; Zhou, Z.; Zhang, J.; Si, X. A survey on life prediction of equipment. Chinese J. Aeronaut. 2015, 28, 25-33. [CrossRef]

33. De Jonge, B.; Scarf, P.A. A review on maintenance optimization. Eur. J. Oper. Res. 2020, 285, 805-824. [CrossRef]

34. Tang, Y.; Zhou, M.C.; Zussman, E.; Caudill, R. Disassembly modeling, planning, and application. J. Manuf. Syst. 2002, $21,200-217$. [CrossRef]

35. Khan, M.A.; Wuest, T. Towards a framework to design upgradable product service systems. Procedia CIRP 2018, 78, 400-405. [CrossRef]

36. Alamerew, Y.A.; Brissaud, D. Circular economy assessment tool for end of life product recovery strategies. J. Remanufacturing 2019, 9, 169-185. [CrossRef]

37. Blomsma, F.; Pieroni, M.; Kravchenko, M.; Pigosso, D.C.A.; Hildenbrand, J.; Kristinsdottir, A.R.; Kristoffersen, E.; Shabazi, S.; Nielsen, K.D.; Jönbrink, A.K.; et al. Developing a circular strategies framework for manufacturing companies to support circular economy-oriented innovation. J. Clean. Prod. 2019, 241. [CrossRef]

38. Blomsma, F.; Kjaer, L.; Pigosso, D.; McAloone, T.; Lloyd, S. Exploring Circular Strategy Combinations-Towards Understanding the Role of PSS. Procedia CIRP 2018, 69, 752-757. [CrossRef]

39. Um, J.; Suh, S.H. Design method for developing a product recovery management system based on life cycle information. Int. J. Precis. Eng. Manuf. Green Technol. 2015, 2, 173-187. [CrossRef]

40. Morseletto, P. Targets for a circular economy. Resour. Conserv. Recycl. 2020, 153, 104553. [CrossRef]

41. Dehghanbaghi, M.; Hosseininasab, H.; Sadeghieh, A. A hybrid approach to support recovery strategies (A case study). J. Clean. Prod. 2016, 113, 717-729. [CrossRef]

42. Thierry, M.; Salomon, M.; van Nunen, J.; van Wassenhove, L. Strategic Issues in Product Recovery Management. Calif. Manag. Rev. 1995, 37, 114-135. [CrossRef]

43. Go, T.F.; Wahab, D.A.; Hishamuddin, H. Multiple generation life-cycles for product sustainability: The way forward. J. Clean. Prod. 2015, 95, 16-29. [CrossRef] 
44. Bauer, T.; Mandil, G.; Naveaux, É.; Zwolinski, P. Lifespan Extension for Environmental Benefits: A new Concept of Products with Several Distinct Usage Phases. Procedia CIRP 2016, 47, 430-435. [CrossRef]

45. Bocken, N.; de Pauw, I.; Bakker, C.A.; van der Grinten, B. Product design and business model strategies for a circular economy. J. Ind. Prod. Eng. 2016, 33, 308-320. [CrossRef]

46. Den Hollander, M.C.; Bakker, C. A business model framework for product life extension. In Proceedings of the 17th International Conference Sustainable Innovation 2012, Bonn, Germany, 29-30 October 2012; pp. 110-118.

47. Paterson, D.A.P.; Ijomah, W.L.; Windmill, J.F.C. End-of-life decision tool with emphasis on remanufacturing. J. Clean. Prod. 2017, 148, 653-664. [CrossRef]

48. Gharfalkar, M.; Ali, Z.; Hillier, G. Clarifying the disagreements on various reuse options: Repair, recondition, refurbish and remanufacture. Waste Manag. Res. 2016, 34, 995-1005. [CrossRef] [PubMed]

49. Linton, J.D.; Jayaraman, V. A framework for identifying differences and similarities in the managerial competencies associated with different modes of product life extension. Int. J. Prod. Res. 2005, 43, 1807-1829. [CrossRef]

50. Ziout, A.; Azab, A.; Atwan, M. A holistic approach for decision on selection of end-of-life products recovery options. J. Clean Prod. 2014, 65, 497-516. [CrossRef]

51. Mulders, M.; Haarman, M. Predictive Maintenance 4.0, Predict the Unpredictable; PricewaterhouseCoopers: London, UK, 2017; Available online: https:/ / www.pwc.be/en/documents/20171016-predictive-maintenance-4-0.pdf (accessed on 15 December 2020).

52. Vermeulen, W.J.V.; Reike, D.; Witjes, S. Circular Economy 3.0: Getting Beyond the Messy Conceptualization of Circularity and the 3R's, $4 R^{\prime}$ s and More ... CEC4Europe Factbook; Circular Economy Coalition for Europe: Vienna, Austria, 2018; pp. 1-6.

53. Kobayashi, H. Strategic evolution of eco-products: A product life cycle planning methodology. Res. Eng. Des. 2005, 16, 1-16. [CrossRef]

54. Bakker, J.D.; van der Graaf, H.J.; van Noortwijk, J.M. Model of lifetime-extending maintenance. In Proceedings of the 8th International Conference on Structural Faults and Repair, London, UK, 13-15 July 1999; pp. 13-15.

55. Moraga, G.; Huysveld, S.; Mathieux, F.; Blengini, G.A.; Alaerts, L.; Van Acker, K.; de Meester, S.; Dewulf, J. Circular economy indicators: What do they measure? Resour. Conserv. Recycl. 2019, 146, 452-461. [CrossRef]

56. Rezinskikh, V.F.; Grin', E.A. Modern problems concerned with ensuring safe operation of heat-generating and mechanical equipment in extending its lifetime. Therm. Eng. 2013, 60, 16-23. [CrossRef]

57. Simons, M. Comparing Industrial Cluster Cases to Define Upgrade Business Models for a Circular Economy. In Dynamics of Long-Life Assets; Springer: Cham, Switzerland, 2017; pp. 1-356. [CrossRef]

58. Barberá, L.; Crespo, A.; Viveros, P.; Stegmaier, R. Advanced model for maintenance management in a continuous improvement cycle: Integration into the business strategy. Int. J. Syst. Assur. Eng. Manag. 2012, 3, 47-63. [CrossRef]

59. Giudice, F.; La Rosa, G.; Risitano, A. Product Recovery-Cycles Design. Extension of Useful Life; Springer: Berlin, Germany, 2003; pp. 165-185.

60. March, S.T.; Scudder, G.D. Predictive maintenance: Strategic use of IT in manufacturing organizations. Inf. Syst. Front. 2019, 21, 327-341. [CrossRef]

61. Coulon, A.; Fondrat, J.; Vincent, N.; Négrier, P.; Renard, J.C. Life extension approach focusing on industrial and railway applications. Procedia Struct. Integr. 2019, 19, 665-673. [CrossRef]

62. Moseichuk, V.; Bashkite, V.; Karaulova, T. Lifecycle extension for industrial equipment. In Proceedings of the 7th International Conference of DAAAM Baltic Industrial Engineering, Tallinn, Estonia, 22-24 April 2010.

63. Mourtzis, D.; Angelopoulos, J.; Boli, N. Maintenance assistance application of Engineering to Order manufacturing equipment: A Product Service System (PSS) approach. IFAC-PapersOnLine 2018, 51, 217-222. [CrossRef]

64. Wu, H.; Huang, A.; Sutherland, J.W. Avoiding Environmental Consequences of Equipment Failure via an LSTM-Based Model for Predictive Maintenance. Procedia Manuf. 2020, 43, 666-673. [CrossRef]

65. Wang, Y.; Deng, C.; Wu, J.; Wang, Y.; Xiong, Y. A corrective maintenance scheme for engineering equipment. Eng. Fail. Anal. 2014, 36, 269-283. [CrossRef]

66. Khan, M.A.; West, S.; Wuest, T. Midlife upgrade of capital equipment: A servitization-enabled, value-adding alternative to traditional equipment replacement strategies. CIRP J. Manuf. Sci. Technol. 2020, 29, 232-244. [CrossRef]

67. Guerra, C.J.; Dinh, A.T.; Camargo, C.E. A maintenance production tool for support equipment lifecycle management. In Proceedings of the 2016 IEEE AUTOTESTCON, Anaheim, CA, USA, 12-15 September 2016; pp. 1-8.

68. Yin, L.; He, M.L.; Xie, W.B.; Yuan, F.; Chen, D.B.; Su, Y. A quantitative model of universalization, serialization and modularization on equipment systems. Phys. A Stat. Mech. Its Appl. 2018, 508, 359-366. [CrossRef]

69. Mesa, J.; González-Quiroga, A.; Maury, H. Developing an indicator for material selection based on durability and environmental footprint: A Circular Economy perspective. Resour. Conserv. Recycl. 2020, 160, 104887. [CrossRef]

70. Abdi, A.; Taghipour, S. Sustainable asset management: A repair-replacement decision model considering environmental impacts, maintenance quality, and risk. Comput. Ind. Eng. 2019, 136, 117-134. [CrossRef]

71. Zwolinski, P.; Brissaud, D. Remanufacturing strategies to support product design and redesign. J. Eng. Des. 2008, 19, 321-335. [CrossRef]

72. Zwolinski, P.; Lopez-Ontiveros, M.A.; Brissaud, D. Integrated design of remanufacturable products based on product profiles. J. Clean. Prod. 2006, 14, 1333-1345. [CrossRef] 
73. Favi, C.; Marconi, M.; Germani, M.; Mandolini, M. A design for disassembly tool oriented to mechatronic product demanufacturing and recycling. Adv. Eng. Inform. 2019, 39, 62-79. [CrossRef]

74. Favi, C.; Germani, M.; Luzi, A.; Mandolini, M.; Marconi, M. A design for EoL approach and metrics to favour closed-loop scenarios for products. Int. J. Sustain. Eng. 2017, 10, 136-146. [CrossRef]

75. Hu, C.; Pei, H.; Wang, Z.; Si, X.; Zhang, Z. A new remaining useful life estimation method for equipment subjected to intervention of imperfect maintenance activities. Chin. J. Aeronaut. 2018, 31, 514-528. [CrossRef]

76. Alcayaga, A.; Wiener, M.; Hansen, E.G. Towards a framework of smart-circular systems: An integrative literature review. J. Clean. Prod. 2019, 221, 622-634. [CrossRef]

77. Ingemarsdotter, E.; Jamsin, E.; Kortuem, G.; Balkenende, R. Circular strategies enabled by the internet of things-A framework and analysis of current practice. Sustainability 2019, 11, 5689. [CrossRef]

78. Okorie, O.; Salonitis, K.; Charnley, F.; Moreno, M.; Turner, C.; Tiwari, A. Digitisation and the circular economy: A review of current research and future trends. Energies 2018, 11, 3009. [CrossRef]

79. Ghoreishi, M.; Happonen, A. New promises AI brings into circular economy accelerated product design: A review on supporting literature. E3S Web Conf. 2020, 158, 1-10. [CrossRef]

80. Ospina, J.; Gallagher, J.; Maher, P. Lifetime Extension by Design and a Fab Lab Level Digital Manufacturing Strategy: Tablet Case Study. In Proceedings of the 3rd PLATE Conference, Berlin, Germany, 18-20 September 2019; pp. 18-20.

81. Alcayaga, A.; Hansen, E.G. Smart-circular systems: A service business model perspective. Prod. Lifetimes Environ. 2017, 10-13. [CrossRef]

82. Kan, C.; Anumba, C.J. Digital Twins as the Next Phase of Cyber-Physical Systems in Construction. In Proceedings of the 2019 ASCE International Conference on Computing in Civil Engineering, Atlanta, GA, USA, 17-19 June 2019; pp. $256-264$.

83. Hoffmann, M.W.; Wildermuth, S.; Gitzel, R.; Boyaci, A.; Gebhardt, J.; Kaul, H.; Amihai, I.; Forg, B.; Suriyah, M.; Leibfried, T.; et al. Integration of novel sensors and machine learning for predictive maintenance in medium voltage switchgear to enable the energy and mobility revolutions. Sensors 2020, 20, 2099. [CrossRef]

84. Ingemarsdotter, E.; Jamsin, E.; Balkenende, R. Opportunities and challenges in IoT-enabled circular business model implementation-A case study. Resour. Conserv. Recycl. 2020, 162, 105047. [CrossRef]

85. Hickey, S.; Fitzpatrick, C. Signalling information from embedded sensors to promote lifetime extension in electrical and electronic equipment. J. Phys. Conf. Ser. 2007, 76. [CrossRef]

86. Jensen, J.P.; Remmen, A. Enabling Circular Economy Through Product Stewardship. Procedia Manuf. 2017, 8, 377-384. [CrossRef]

87. Tygesen, U.T.; Jepsen, M.S.; Vestermark, J.; Dollerup, N.; Pedersen, A. The True Digital Twin Concept for Fatigue Re-Assessment of Marine Structures. In Proceedings of the ASME 2018 37th International Conference on Ocean, Offshore and Arctic Engineering. Volume 1: Offshore Technology, Madrid, Spain, 17-22 June 2018; pp. 1-11.

88. Klishin, V.I.; Gerike, B.L.; Mokrushev, A.A. The Development of Digital Technologies in Mining Machinery Technical Maintenance. IOP Conf. Ser. Mater. Sci. Eng. 2020, 795. [CrossRef]

89. Wang, J.; Ye, L.; Gao, R.X.; Li, C.; Zhang, L. Digital Twin for rotating machinery fault diagnosis in smart manufacturing. Int. J. Prod. Res. 2019, 57, 3920-3934. [CrossRef]

90. Andrew, J.M. Digitalization Strategies to Extend Turbine Life. 2019. Available online: https://www.windsystemsmag.com/wpcontent/uploads /2019/12/1219-CW.pdf (accessed on 15 December 2020).

91. Geerken, T.; Schmidt, J.; Boonen, K.; Christis, M.; Merciai, S. Assessment of the potential of a circular economy in open economies-Case of Belgium. J. Clean. Prod. 2019, 227, 683-699. [CrossRef]

92. Saidani, M.; Yannou, B.; Leroy, Y.; Cluzel, F.; Kendall, A. A taxonomy of circular economy indicators. J. Clean. Prod. 2019, 207, 542-559. [CrossRef]

93. Matarrese, P.; Fontana, A.; Sorlini, M.; Diviani, L.; Specht, I.; Maggi, A. Estimating energy consumption of injection moulding for environmental-driven mould design. J. Clean. Prod. 2017, 168, 1505-1512. [CrossRef]

94. Arunraj, N.S.; Maiti, J. Risk-based maintenance-Techniques and applications. J. Hazard. Mater. 2007, 142, 653-661. [CrossRef]

95. Cherepanov, A.P. Concept of methodological recommendations for estimating service life of industrial equipment based on service-life-safety studies. Chem. Pet. Eng. 2012, 47, 790-795. [CrossRef]

96. Barni, A.; Fontana, A.; Menato, S.; Sorlini, M.; Canetta, L.; Barni, A.; Fontana, A.; Menato, S.; Sorlini, M.; Canetta, L. Exploiting the Digital Twin in the Assessment and Optimization of Sustainability Performances. In Proceedings of the International Conference on Intelligent Systems (IS), Madeira, Portugal, 25-27 September 2018; pp. 706-713. 